\title{
Barriers to patient, provider, and caregiver adoption and use of electronic personal health records in chronic care: a systematic review
}

Zahra Niazkhani ${ }^{1,2}$, Esmaeel Toni ${ }^{2,3}$, Mojgan Cheshmekaboodi ${ }^{4}$, Andrew Georgiou ${ }^{5}$ and Habibollah Pirnejad ${ }^{2,6,7^{*}}$ (D)

\begin{abstract}
Background: Electronic personal health records (ePHRs) are defined as electronic applications through which individuals can access, manage, and share health information in a private, secure, and confidential environment. Existing evidence shows their benefits in improving outcomes, especially for chronic disease patients. However, their use has not been as widespread as expected partly due to barriers faced in their adoption and use. We aimed to identify the types of barriers to a patient, provider, and caregiver adoption/use of ePHRs and to analyze their extent in chronic disease care.

Methods: A systematic search in Medline, PubMed, Science Direct, Cumulative Index to Nursing and Allied Health Literature (CINAHL), the Cochrane Central Register of Controlled Trials, and the Institute of Electrical and Electronics Engineers (IEEE) database was performed to find original studies assessing barriers to ePHR adoption/use in chronic care until the end of 2018. Two researchers independently screened and extracted data. We used the PHR adoption model and the Unified Theory of Acceptance and Use of Technology to analyze the results. The Mixed Methods Appraisal Tool (MMAT) version 2018 was used to assess the quality of evidence in the included studies.

Results: Sixty publications met our inclusion criteria. Issues found hindering ePHR adoption/use in chronic disease care were associated with demographic factors (e.g., patient age and gender) along with key variables related to health status, computer literacy, preferences for direct communication, and patient's strategy for coping with a chronic condition; as well as factors related to medical practice/environment (e.g., providers' lack of interest or resistance to adopting ePHRs due to workload, lack of reimbursement, and lack of user training); technological (e.g., concerns over privacy and security, interoperability with electronic health record systems, and lack of customized features for chronic conditions); and chronic disease characteristics (e.g., multiplicities of co-morbid conditions, settings, and providers involved in chronic care).

(Continued on next page)
\end{abstract}

\footnotetext{
* Correspondence: pirnejad.h@umsu.ac.ir

${ }^{2}$ Department of Health Information Technology, Urmia University of Medical Sciences, Urmia, Iran

${ }^{6}$ Patient Safety Research Center, Urmia University of Medical Sciences, Urmia, Iran

Full list of author information is available at the end of the article
}

C C The Author(s). 2020 Open Access This article is licensed under a Creative Commons Attribution 4.0 International License, which permits use, sharing, adaptation, distribution and reproduction in any medium or format, as long as you give appropriate credit to the original author(s) and the source, provide a link to the Creative Commons licence, and indicate if changes were made. The images or other third party material in this article are included in the article's Creative Commons licence, unless indicated otherwise in a credit line to the material. If material is not included in the article's Creative Commons licence and your intended use is not permitted by statutory regulation or exceeds the permitted use, you will need to obtain permission directly from the copyright holder. To view a copy of this licence, visit http://creativecommons.org/licenses/by/4.0/ The Creative Commons Public Domain Dedication waiver (http://creativecommons.org/publicdomain/zero/1.0/) applies to the data made available in this article, unless otherwise stated in a credit line to the data. 
(Continued from previous page)

Conclusions: ePHRs can be meaningfully used in chronic disease care if they are implemented as a component of comprehensive care models specifically developed for this care. Our results provide insight into hurdles and barriers mitigating ePHR adoption/use in chronic disease care. A deeper understating of the interplay between these barriers will provide opportunities that can lead to an enhanced ePHR adoption/use.

Keywords: Personal health records, Systematic reviews, ePHR, Self-care, Chronic diseases

\section{Highlights}

- Evidence points to benefits associated with PHR adoption and uses in chronic conditions

- Barriers to PHR adoption/use, with a special focus in chronic care, has not been well described and understood

- Addressing barriers for PHR adoption/use in chronic care should cross the boundary of patientlevel barriers

- Barriers at the provider and healthcare organization levels should be understood and addressed, thoroughly

- PHRs should fit in the structure of "chronic care models" developed for improving chronic care

\section{Background}

Promoting self-care and patient engagement in care management has gradually become key features in efforts to improve health service delivery and care quality in chronic diseases $[1,2]$. Electronic personal health records (ePHRs) provide the tools to empower patients and promote self-care $[3,4]$. A systematic review found that self-monitoring through ePHR improves health outcomes in chronic conditions [5]. Because of such potentials to enhance quality and patient engagement [6-8], the Health Information Technology for Economic and Clinical Health Act (HITECH) and meaningful use phase 2 and 3 have driven the adoption of ePHRs in parallel to Electronic Health Records (EHRs) [9].

Studies have shown that both patients and providers are interested in ePHRs especially as they find them as a means to increase patient empowerment [10-12]. Yet, there are barriers to overcome and challenges to embrace when adopting ePHRs. Some of these barriers are related to the implementation of EHRs such as EHR products and capital and human resource issues. For example, from 2,674 general hospitals studied in the United States (US) in 2013, only 5.8 percent of hospitals met measures for stage 2 meaningful-use readiness and several other criteria, including sharing care summaries with other providers and providing patients with online access to their data, as necessary functions for a tethered PHR
[13]. Other barriers are more ePHR specific ones such as poorly aligned functionalities with patients' expectations and self-management practices and concerns about privacy and confidentiality of patient information in ePHRs $[14,15]$. Even outside the US healthcare context, similar hurdles have also contributed to a lower adoption rate than what has been expected or hoped for [16]. Such results continue to be reported after the implementation of many health information technologies (HIT) including ePHRs, which highlight a strong need to understand factors and challenges that influence the implementation outcomes [17]. Overcoming these challenges and barriers in implementing and adopting ePHRs can result in increased efficiency and improved quality patient care [18]. Therefore, recognizing and understanding the nature of such barriers is imperative to be well equipped to devise strategies to overcome the barriers and to achieve ePHR's meaningful use.

There have been a few reviews published on the barriers to ePHR adoption and use. A review of the patient-level barriers categorized them into individual, demographic, capability, health-related, ePHR-related, or attitudinal factors [19]. Another review with similar scope concluded that a lack of awareness of and sufficient training regarding portal use were the two main barriers [18]. In the elderly population, the main barriers were limited technology access and no prior knowledge of the existence of a patient portal, and limited health literacy and motivation to use a patient portal [20]. In rural areas of the US, provider resistance, privacy concerns, and the lack of EHRs, interoperability standards, and funding have emerged as the main barriers [21]. However, these reviews have narrowly focused on patient-level barriers [18, 19], or were limited in terms of age ranges [20], time frame, or geographical location reviewed [21, 22]. To our knowledge, there is a significant gap in the literature on the barriers in the patient, caregiver, and provider levels that may impact ePHR adoption and use in the context of chronic care. To address this gap, we aimed to identify and synthesize evidence on ePHR adoption and use barriers in chronic disease care. More specifically, we were interested to identify the types of barriers and to analyze their extent in this care. The 
insights gained will inform efforts for effective design, implementation, and use of ePHRs for a patient population at the most need of these tools.

\section{Methods}

This review was conducted according to the Preferred Reporting Items for Systematic reviews and MetaAnalyses (PRISMA) [23].

\section{Search strategy}

We conducted a literature search in OVID versions of MEDLINE, PubMed, Science Direct, Cumulative Index to Nursing and Allied Health Literature (CINAHL), the Cochrane Central Register of Controlled Trials and the IEEE database for English-language, journal or congress proceedings' full texts published January 1, 2005, till December 31, 2018. We used a Boolean search strategy using keywords and $\mathrm{MeSH}$ terms related to two areas of interest i.e., the intervention (e.g., Personal Health Record OR Personal Medical Record OR patient portal OR patient internet portal, etc.) $A N D$ the health condition (e.g., Chronic Disease OR Chronic Illness, OR Chronic Condition, etc.). The details of our search strategy are accessible in Additional file 1. We also conducted a manual review of all reference lists of included studies and the pertinent ePHR reviews including $[14,15,18-22,24-29]$.

\section{Inclusion and exclusion criteria}

We included studies according to the following inclusion criteria: 1) the intervention was an ePHR/patient portal, 2) the targeted users were chronic disease patients, their caregivers and/or their healthcare professionals, 3) the study was an original research article, and 4) the study design was either quantitative, qualitative, or mixed methods.

We excluded ePHR/patient portals that were not aimed at chronic patients, paper-based ePHRs or educational websites, assistive living technologies, or mHealth tools, systematic reviews, proceedings abstracts, commentaries, editorials, and articles describing theoretical background or design reports without having an evaluation nature. The main reasons for exclusions in each phase of this review are accessible in Additional file 2.

\section{Review procedures and data extraction}

After removing duplicates, our search identified 3088 unique records, which were screened for eligibility. Figure 1 shows the PRISMA flow diagram of our review. Two reviewers (ET and $\mathrm{MCH}$ ) were trained on the screening and data extraction tool by $\mathrm{ZN}$, who is an experienced researcher in conducting systematic reviews in the field. The reviewers reviewed a sample of references and compared extraction results to reach an excellent agreement $(k a p p a=0.77)$. Then, they screened titles and abstracts of the abovementioned search result to find relevant studies based on our inclusion/exclusion criteria. In this phase, 143 potentially eligible publications were selected for the full-text review. Further articles were found through the manual review. All articles were independently reviewed in detail by $\mathrm{ZN}$ and either $\mathrm{ET}$ or $\mathrm{MCH}$. Disagreements were solved by consensus. Endnote version XI was used to manage records.

We extracted the following main study characteristics in the full review phase: general information (e.g., the authors and publication year), study objectives, study design, patient population, system users, the intervention (e.g., the description of ePHRs and their integration with other systems), and the main study results.

\section{The methodological quality of studies}

We used the mixed methods appraisal tool (MMAT) version 2018 to assess the quality of evidence in included studies [30]. This tool can be used to appraise the quality of empirical studies (i.e., primary research based on experiment, observation, or simulation) in three categories of study designs (i.e., qualitative, quantitative, and mixed methods).

\section{Data synthesis}

According to a widely used definition, an ePHR is "an electronic application through which individuals can access, manage and share their health information, and that of others for whom they are authorized, in a private, secure, and confidential environment" [3]. We used two well-known models as a theoretical background to analyze and categorize barriers to ePHR adoption/use faced by users. The first was the "Personal Health Records Adoption Model" (PHRAM), developed through integrating several relevant parent models/theories [31]. This model was used to analyze the barriers faced by patients and caregivers in the context of chronic care. We also used the unified theory of acceptance and use of technology (UTAUT) to analyze barriers specifically experienced by care providers [32]. Since conducting a meta-analysis became out of the scope of this study due to the lack of unified quantitative data in included studies, we only provide a narrative description of results based on the PHRAM and UTAUT.

\section{Results}

\section{Characteristics of included studies}

Our review identified 60 ePHR studies [5, 10, 12, 33-89], among which 24 were qualitative, 22 quantitative, and 14 mixed methods studies. Additional file 4 provides the details of the included studies. These studies were conducted between 2006 and 2018, nine of them in the single year of 2015. Forty-six studies were from the US, followed by five 
studies in Canada, two studies in the Netherlands, two in the United Kingdom, and the remaining five in Denmark, Sweden, Germany, New Zealand, and Argentina (one study from each country). A majority of studies included older patient populations (compared with younger patients) and diabetics (compared to other chronic patients) in their evaluations. Ten studies had a target population of pediatrics [37-39, 43, 44, 59, 71, 72, 78, 85]. The results are provided here according to the personal, environmen$\mathrm{tal} /$ medical practice, technological, and chronic disease factors on the bases of the PHRAM and UTAUT.

\section{Personal factors}

In one study involving survivors of pediatric cancers, referring to the issue of age, cancer survivors $>18$ years old were significantly more likely to use an ePHR compared to those $<18$ [85]. While a high proportion of patients with age 50 and older had higher frequency and intensity of ePHR use [66], patients over the age of 65 were less likely to intend to use an ePHR [10], and patients aged over 70 were associated with a lack of use [70]. In four studies, more men than women had access to computers or the internet, expressed confidence in using ePHRs, or used it [54,67, 74, 84], while females were the dominant users in three studies $[48,66,89]$.

People with minority race/ethnicity (including AfricanAmerican, Latino, and Filipino) reported more negative attitudes towards ePHRs, were less likely to use ePHRs and experienced more obstacles compared to Whites and Caucasians [34, 47, 48, 55, 57, 61, 65, 66, 69, 70, 74, 75, 85]. Having a paid job or higher income and living in a higher socioeconomic neighborhood, and being insured were associated with higher use (reported in studies from the US and the Netherlands) [42, 61, 66, 67, 75, 84]; while, having a lower income and being below the poverty level were linked to non-use [34, 48].

Patients with lower educational attainments were less likely to intend to use or use an ePHR [10,34, 42, 48, 61, $65,67,69,70,74,75]$. Patients with limited health literacy were less likely to use ePHR or use it ineffectively [5, 34, $41,46,54,65,69,74,76,77,87]$. The level of knowledge, self-efficacy, and confidence in technology use was associated with ePHR adoption/use [52, 54, 56, 67, 83].

Negative attitudes toward the disease and health care experiences in general, and ePHRs in particular, prevented patients from using ePHRs [10, 40, 44, 47, 59, 71]. Patients were concerned about the reliability of ePHRs to facilitate timely and productive communication with providers [37, $43,65,81]$. In one study, patients commonly expressed negative attitudes partly because of their experience of confusion and misunderstanding [40].

Fourteen studies highlighted the critical role of computer/technology literacy and skills to effectively use
ePHRs [5, 41, 42, 45, 49, 52, 56, 65, 68, 76, 82, 83, 86, 87]. Computer literacy barriers included, but were not limited to, the lack of basic computer skills, inexperience in using search bars or uniform resource locators, difficulty while navigating the portal, and negative experiences with online security breaches/viruses. Three studies noted that computer anxiety negatively affected patients' behavioral intention to adopt ePHRs $[5,34,86]$.

Challenges related to communication preferences were brought up in several studies with a majority pointing out the value of in-person, or telephone contacts between patients and providers [37-40, 44, 47-49, 52, 58, 59, 64, 65, $76,78-80,82,86]$. The main reasons for such a preference were getting anxious when seeing results online and concerns over technology replacing their providers. The preference for in-person communications was also shared by providers in certain circumstances $[64,80]$.

\section{Environmental/medical practice factors Social influence}

The impact of the social influence of "important others" (i.e., family members and care providers) on patients was evident $[12,54,55]$. It was shown that living alone and being not currently married were associated with nonadoption and lesser ePHR use [34, 42, 67]. Moreover, studies pointed out the role of providers' willingness to use portals, their communication about it, and their level of use in patients' initial portal use [47, 59, 81, 84]. While patients wanted their physicians to get more involved in ePHRs [79], physicians viewed them as more of a patient, receptionist, or nurse tool $[68,79]$.

\section{Facilitating/impending conditions}

Our review identified the existence or otherwise lack of the following organizational and/or technical infrastructures to support or impede ePHR use: being in an organization's priority list, integration into the EHRs, patients ready access to resources such as computers, the Internet, and ePHRs, adequate technical support, and proper training on ePHR use $[5,10,12,34,42,46$, 50-52, 56, 60, 64, 65, 76, 84, 88].

Due to its impacts on physician's time management and workload, "physician resistance" was mentioned as "the greatest barrier to ePHR implementation" [12]. There were also concerns about the impacts on providers' available time for care, lack of reimbursement, or professional liability issues [36, 64, 68]. Physicians voiced their concerns about excess time and efforts to handle issues related to the ePHRs due to lack of integration with EHRs $[79,80]$.

\section{Incentive motivation}

Tangible incentives and cost compensations, or otherwise lack thereof, were also an important factor [12, 54, 


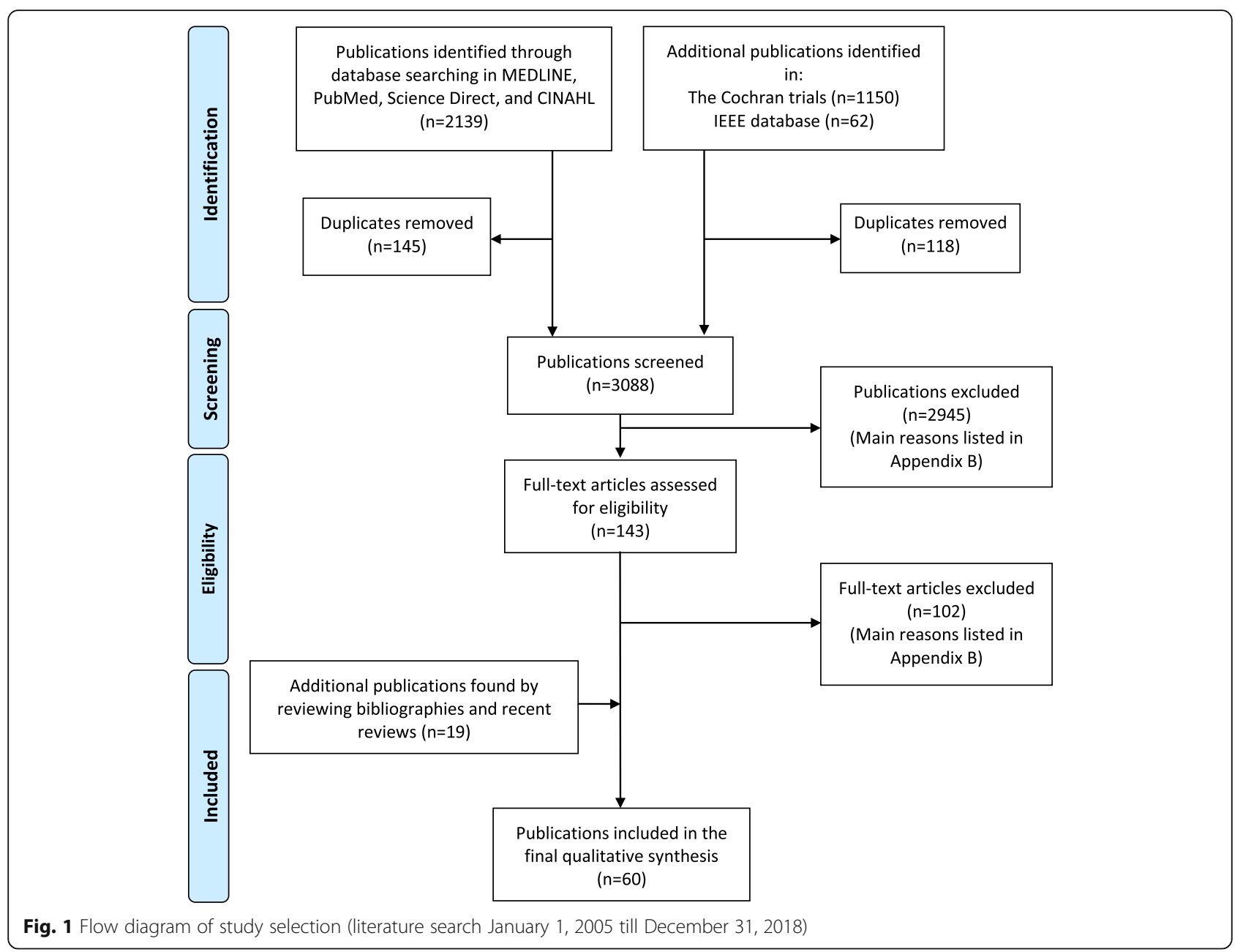

$64,65]$. For example, it was important to be certain about how ePHR-related services would be paid for, who would pay, and under what circumstances [41]. The cost of services was also mentioned as a barrier by patients $[76,83,88]$.

\section{Technology factors}

This section provides the results related to the perceived usefulness of ePHRs, perception of external control, compatibility, and perceived complexity.

\section{Perceived usefulness}

Perceived usefulness featured as a key driving factor for the intention to use ePHRs $[10,49,59,65,79,80]$. For example, non-users mostly expressed concerns about simply not seeing the value of using a portal to manage their health or lack of personalization in using this technology [65].

\section{Perception of external control}

Preserving general privacy, confidentiality, and security of health records was one of the most common concerns regarding ePHR use (e.g., confidentially of a stigmatized or sensitive condition, or confidentiality and security of information easily accessible to researchers and industry members, and misuse of information by insurance companies to deny coverage) $[10,45-47,52,58,65,68,72$, $76,78,87,88]$. Patients voiced their concerns about caregiver's access to their information and requested appropriate access limitation [52, 53, 68]. Clinicians' attitudes towards caregiver involvement in ePHR use were controversial in one study: while $28.3 \%$ favored it, $32.1 \%$ disagreed because it impaired patients' privacy [80].

Moreover, patients reported frustration at several instances in which their profile, medication list, lab results or medical history were incorrect or missing in the ePHR but they were unable to correct them $[46,50,64]$

\section{Compatibility}

The degree to which an ePHR was perceived as being consistent with the existing values, past experiences, and needs of its potential adopters i.e., chronic patients and their caregivers and providers were mentioned as an important factor for adoption in some studies [36, 40, 44, 


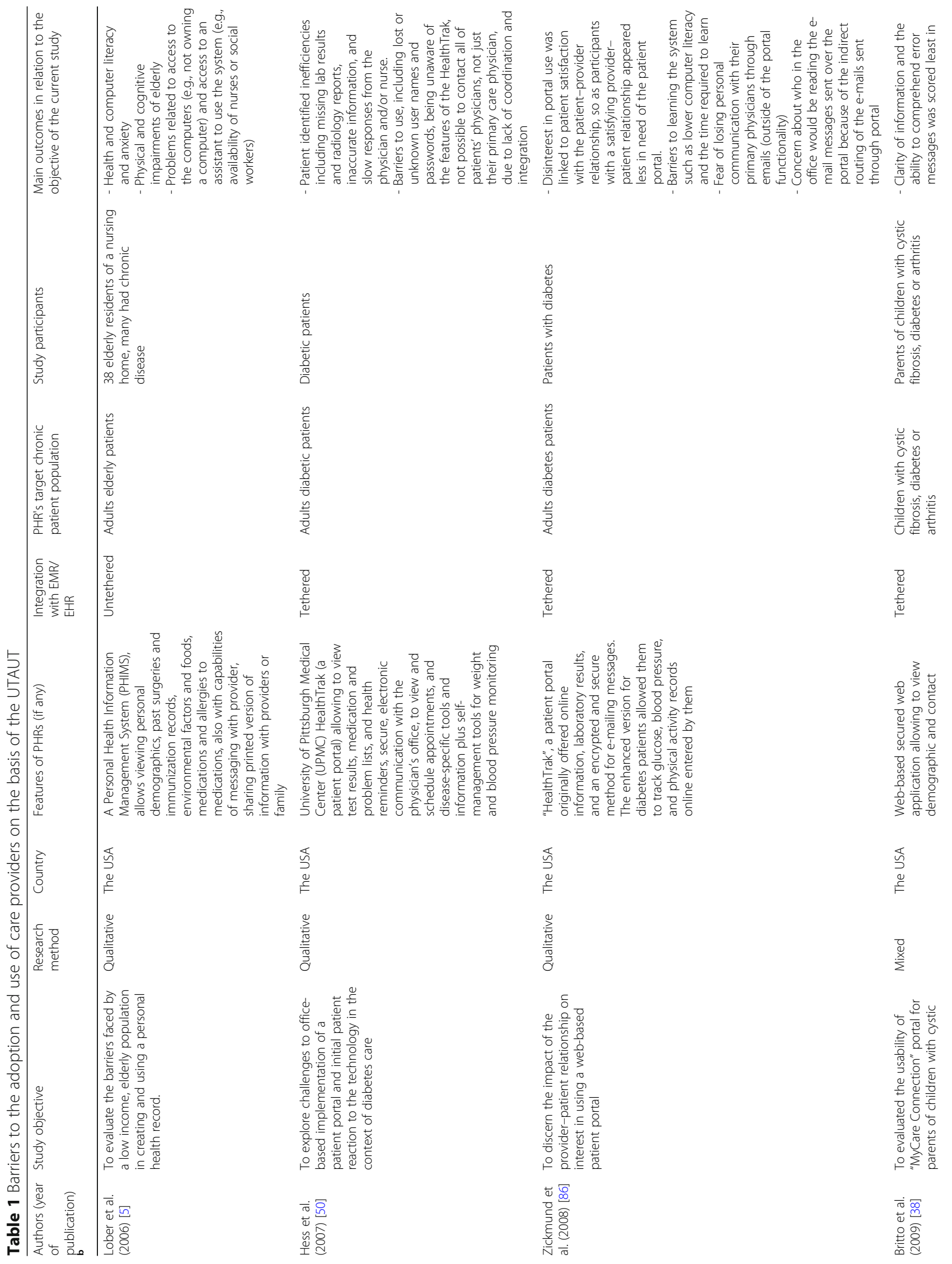




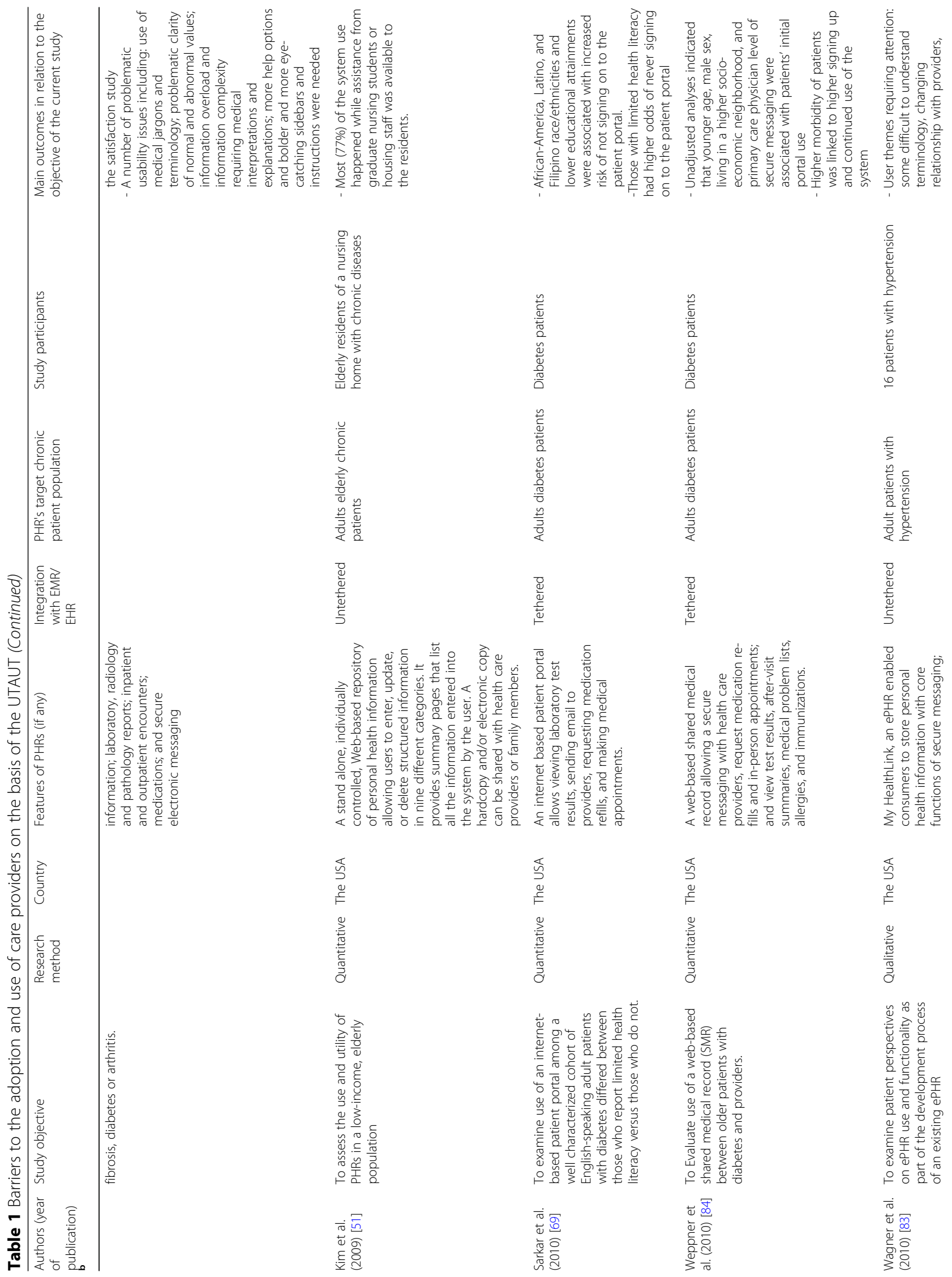




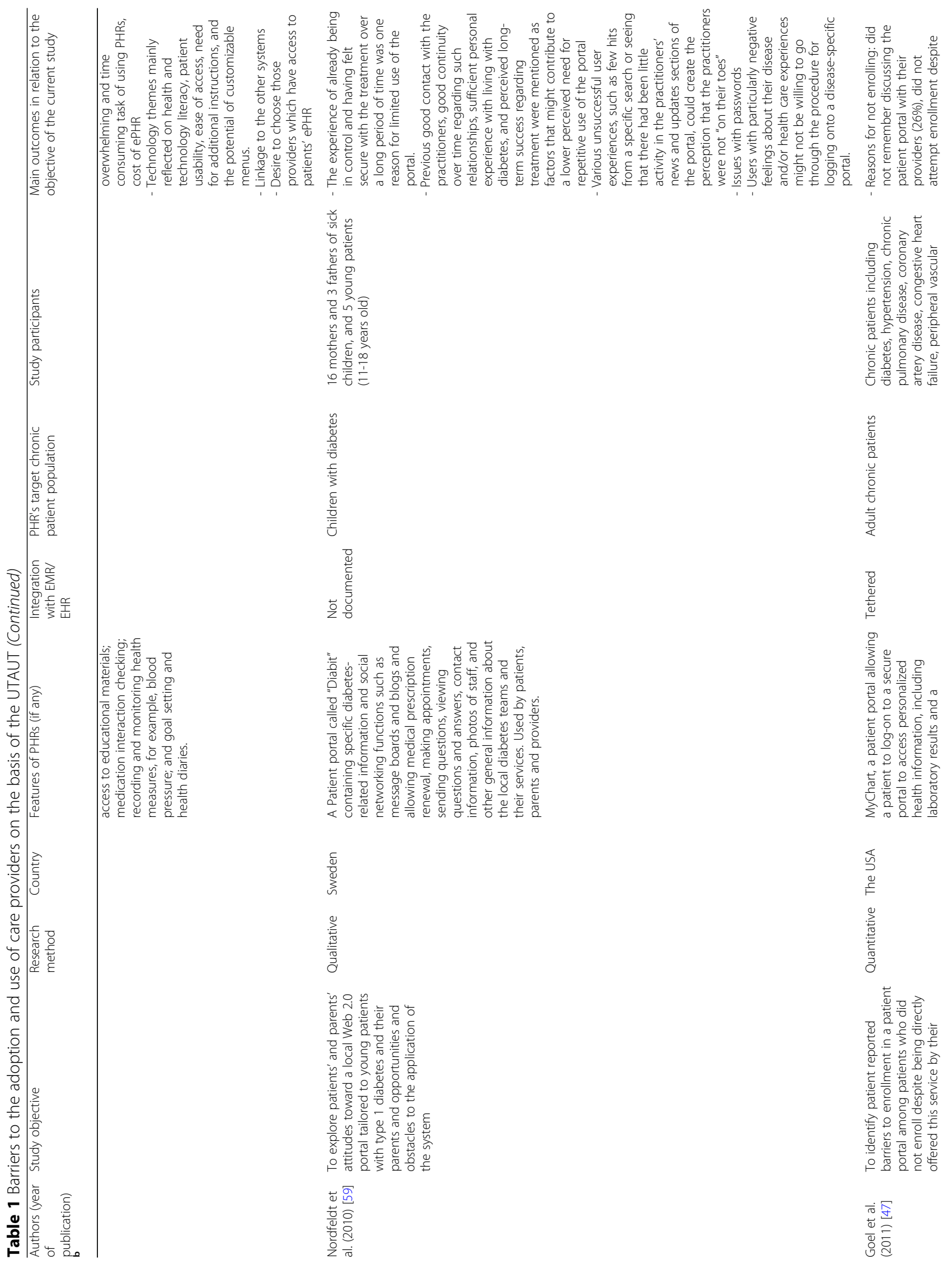




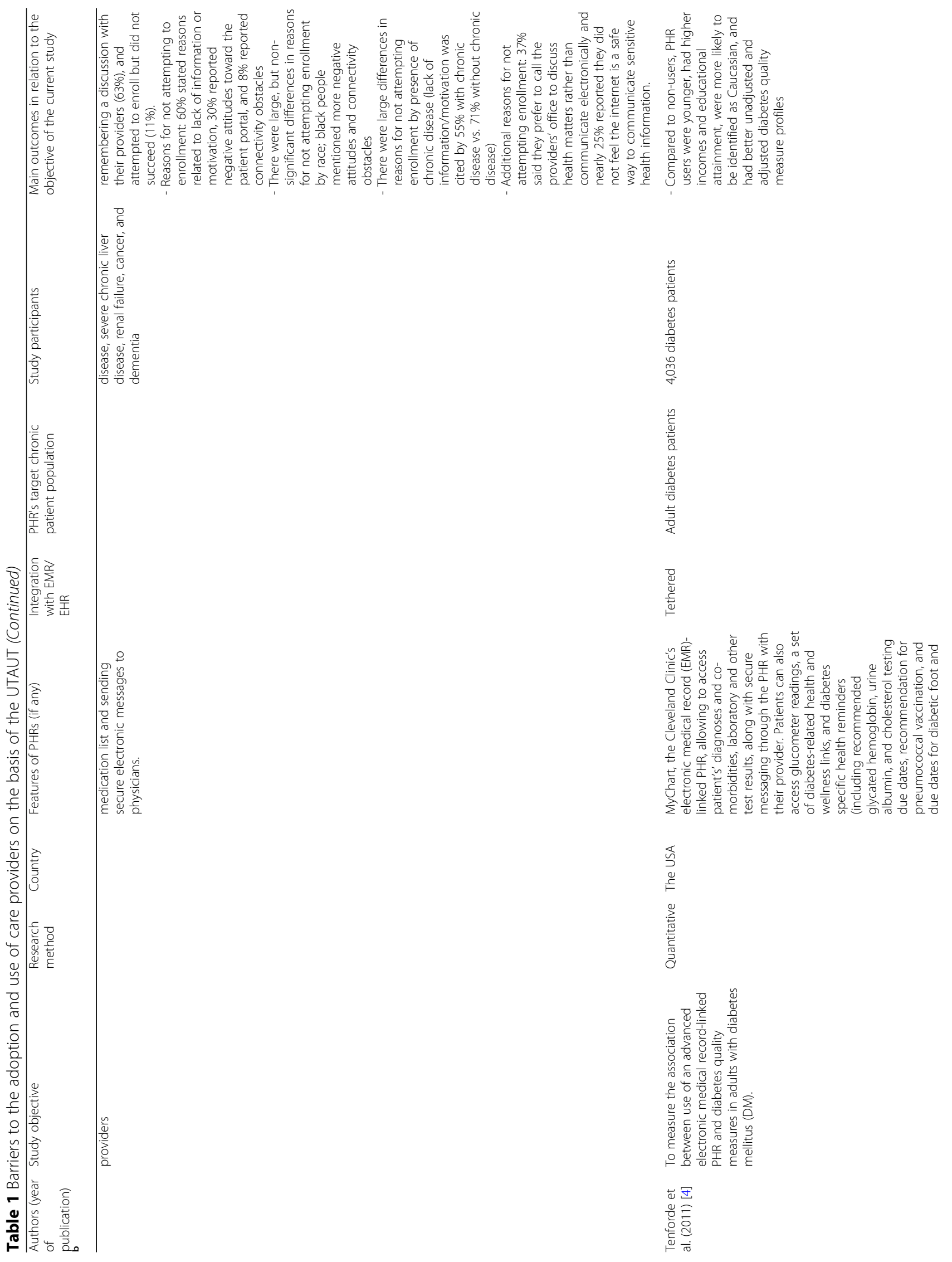




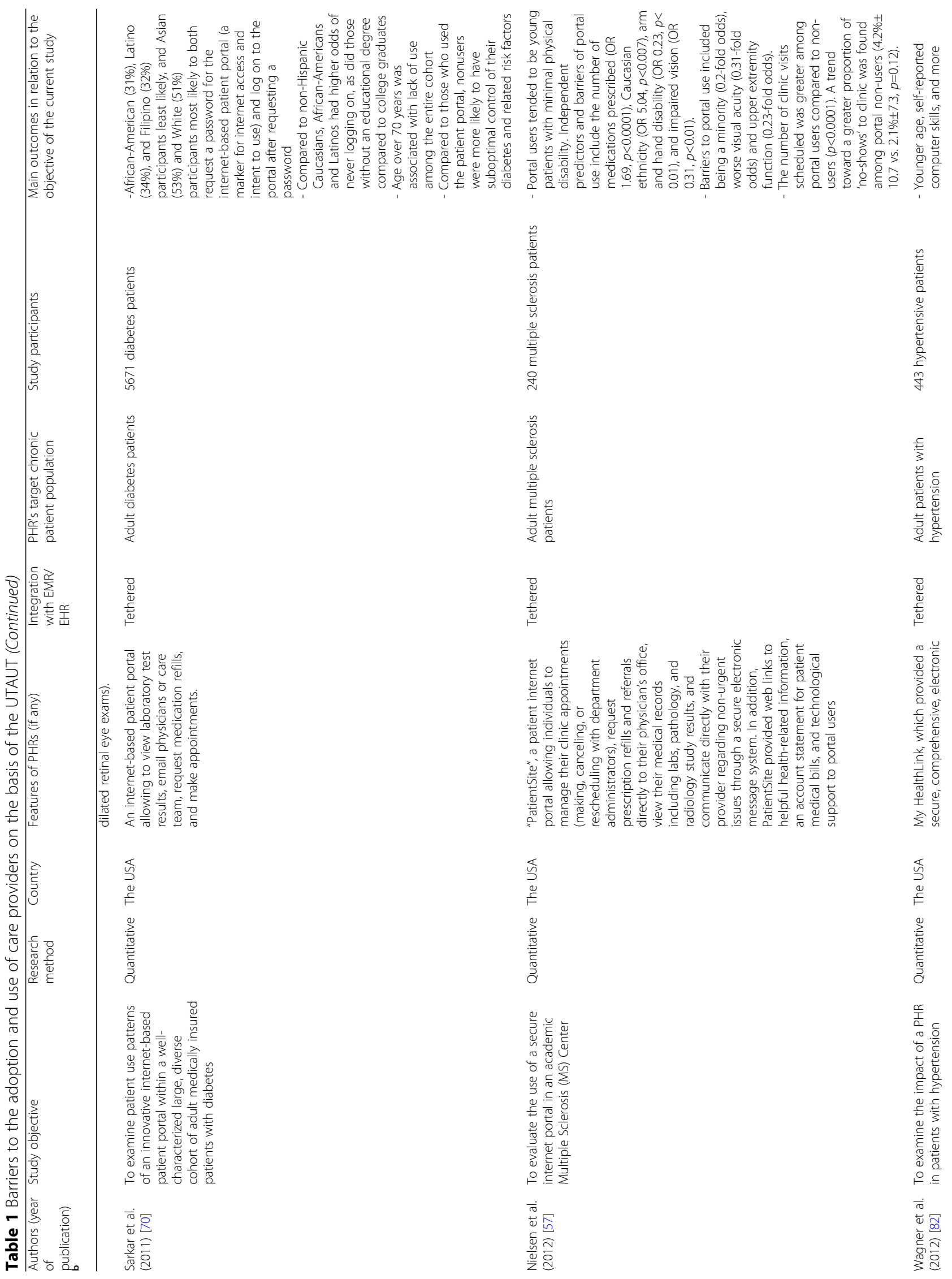




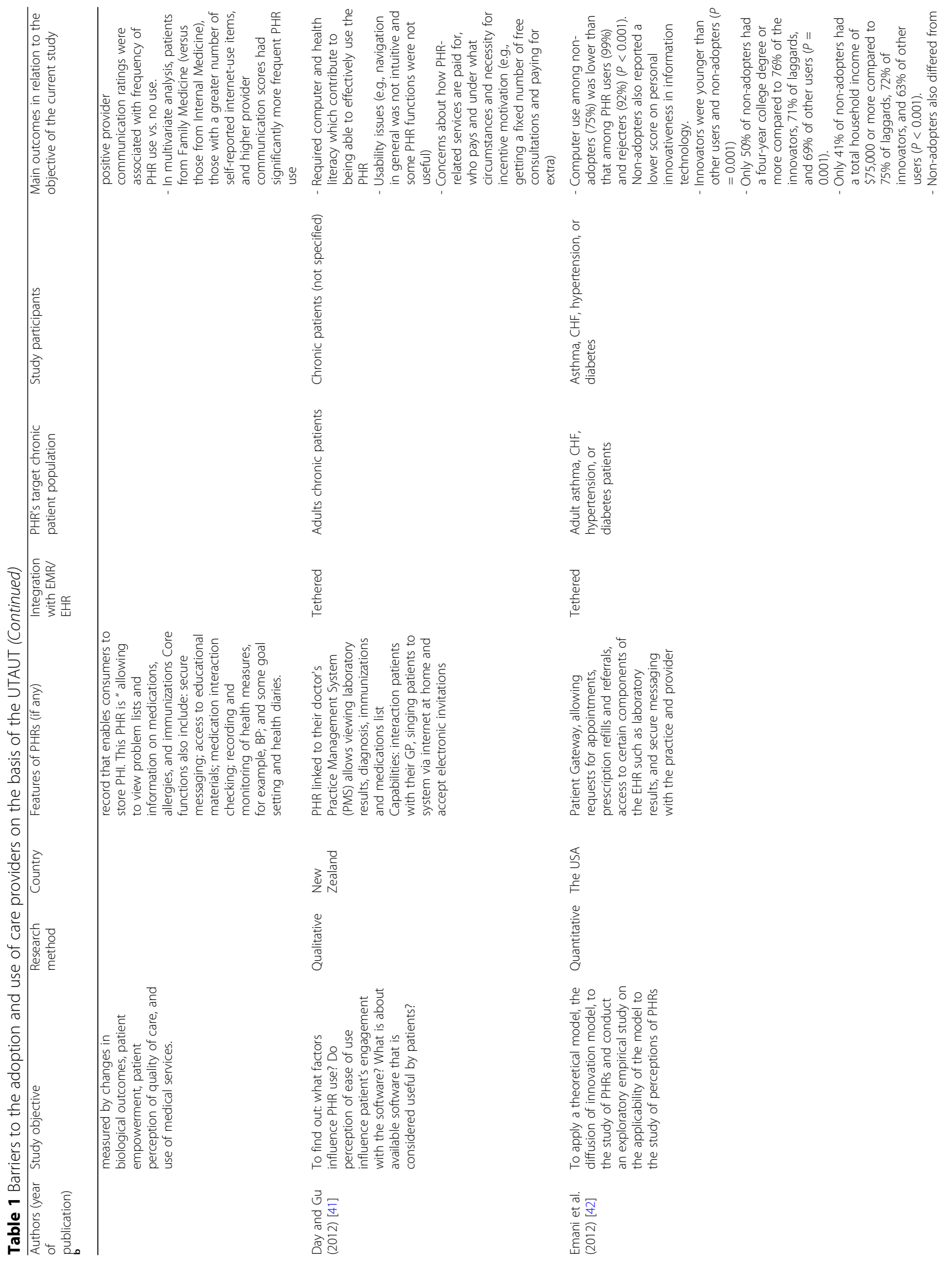




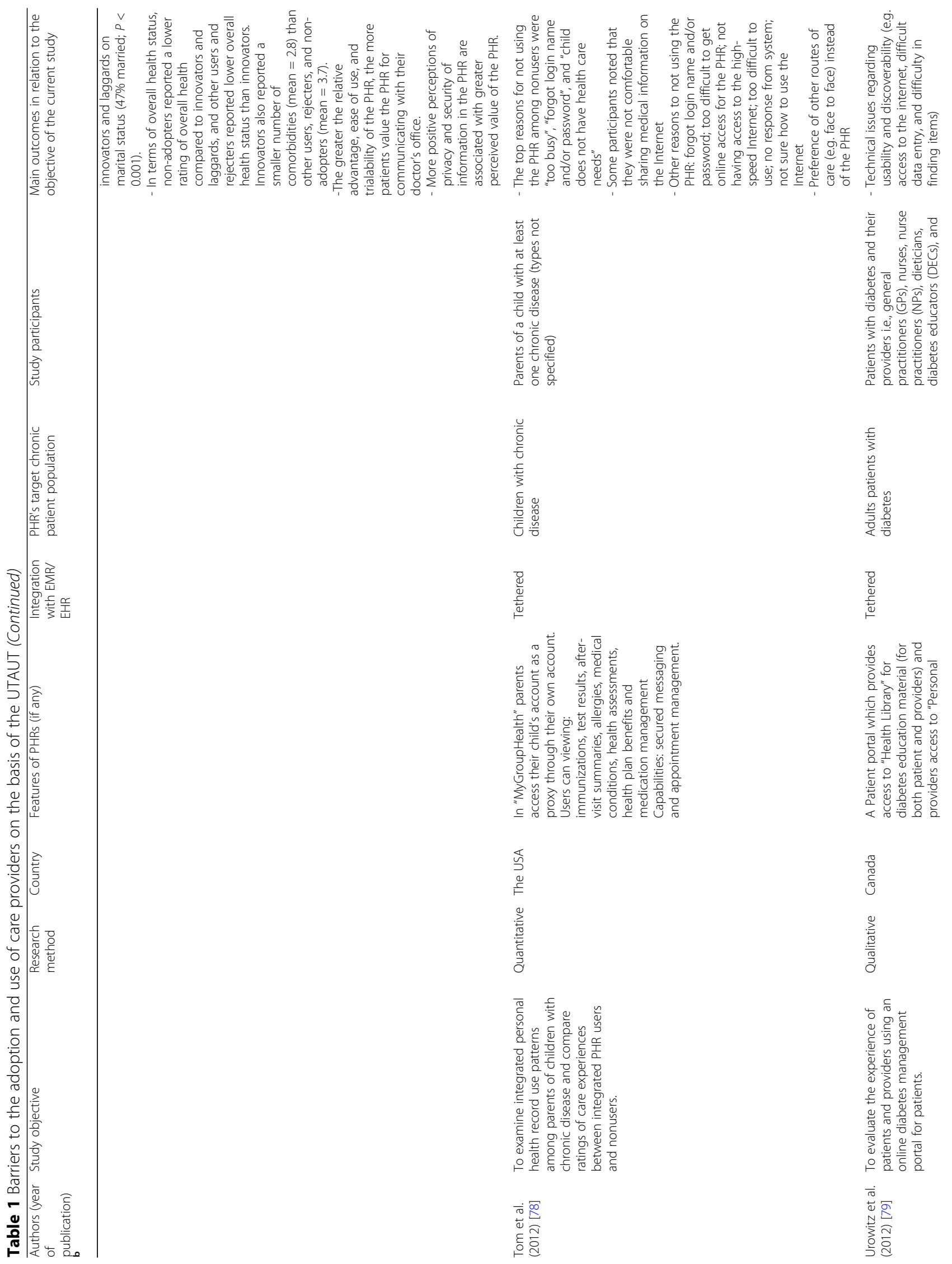




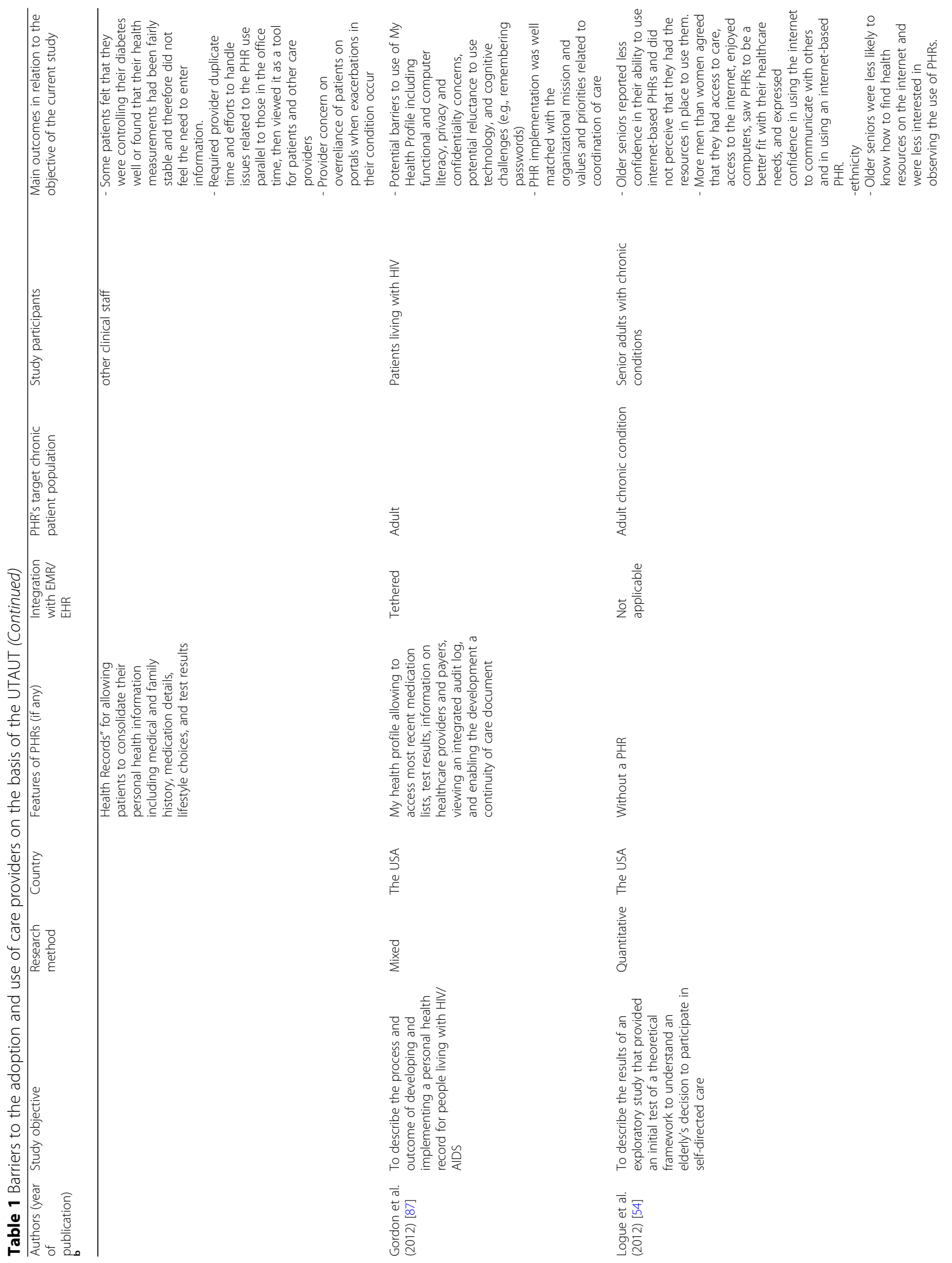




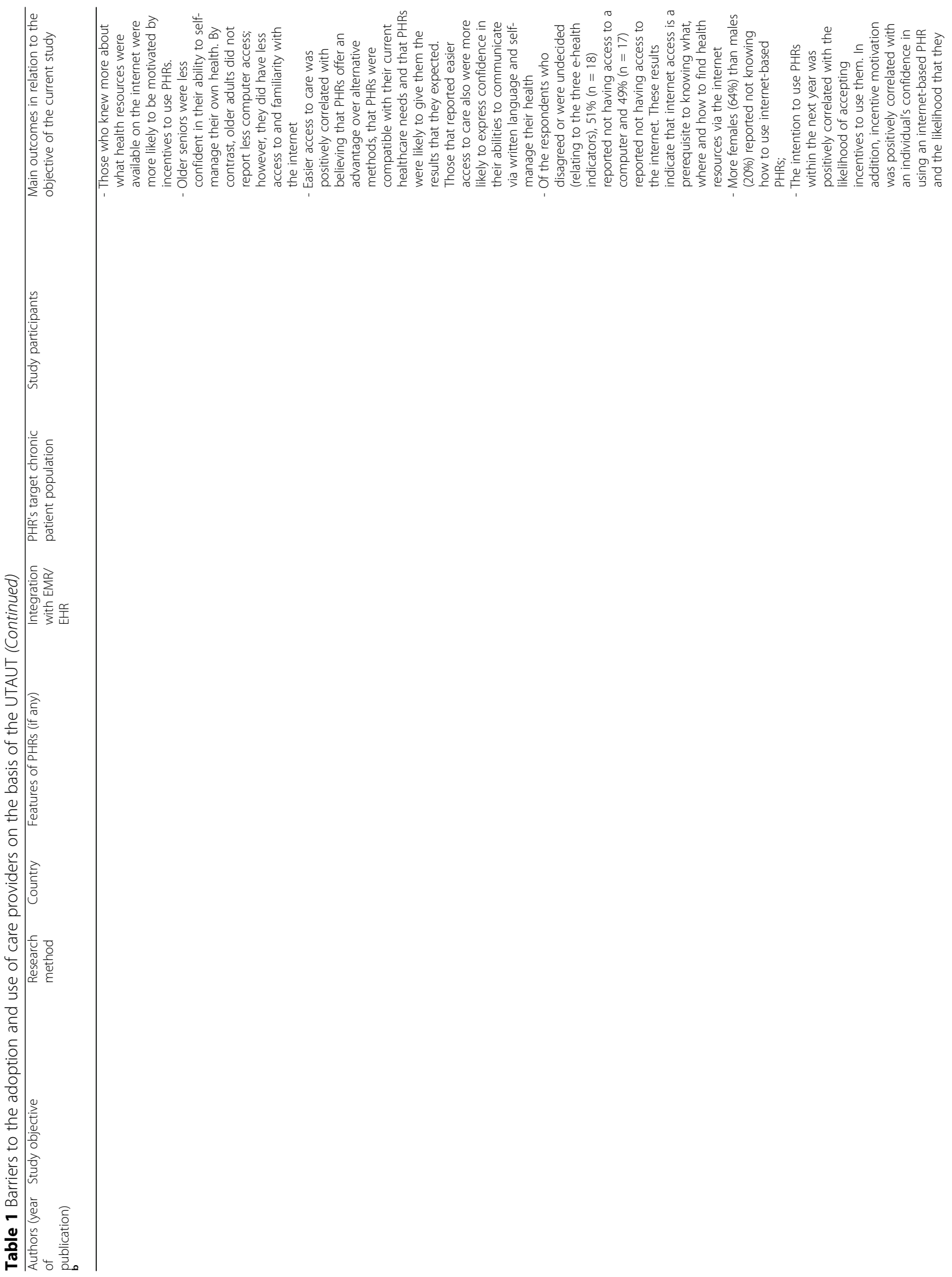




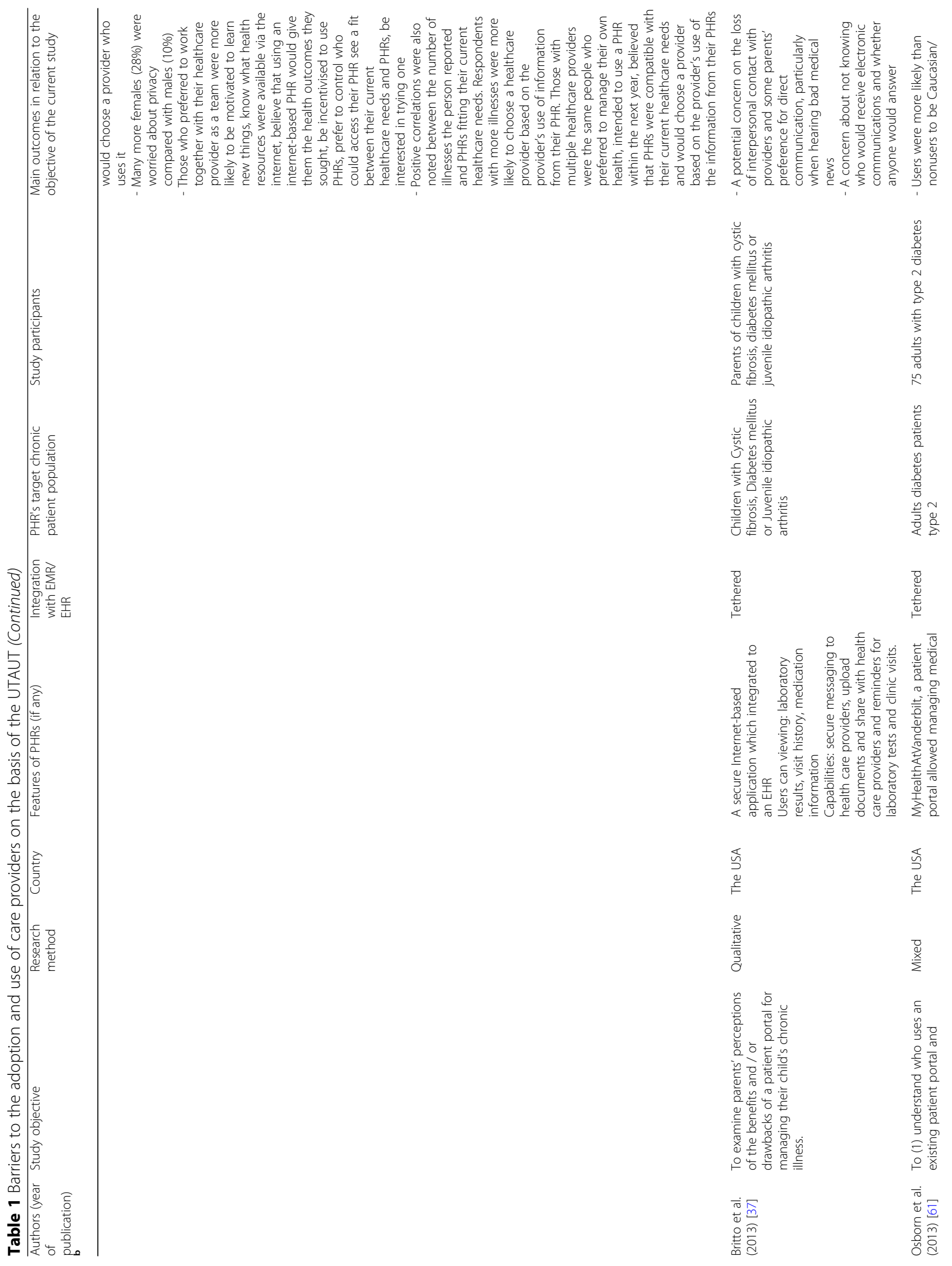




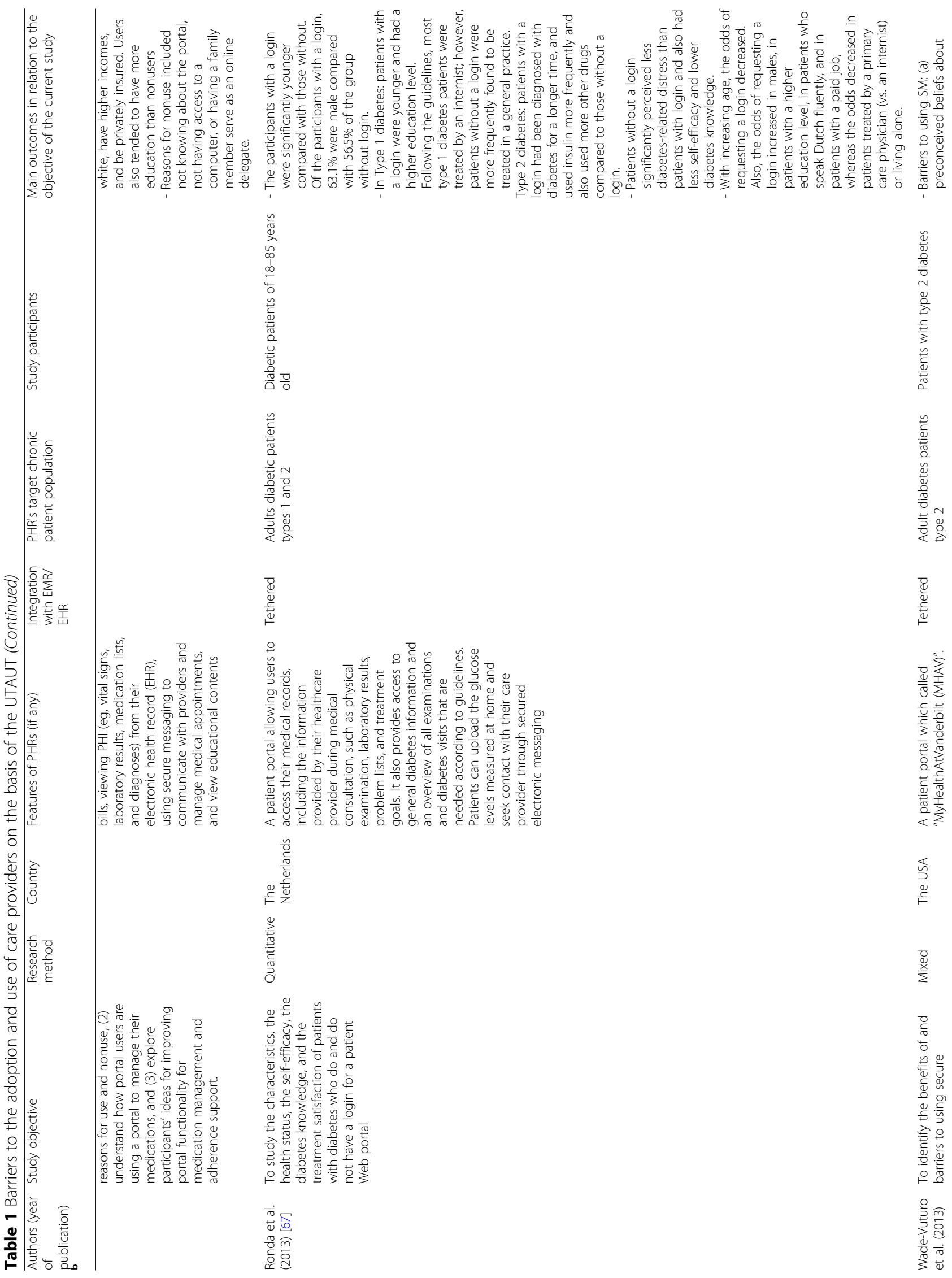




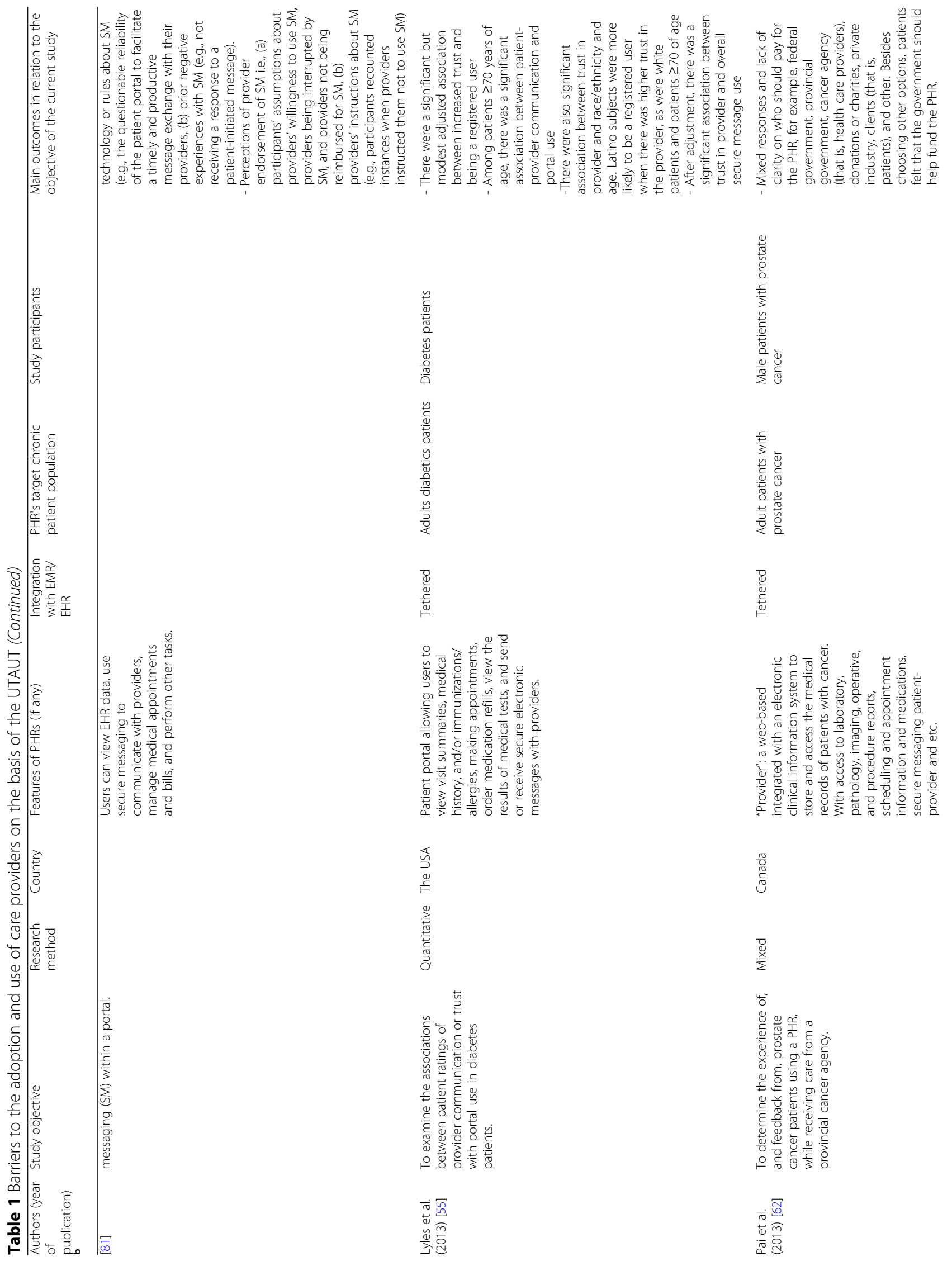




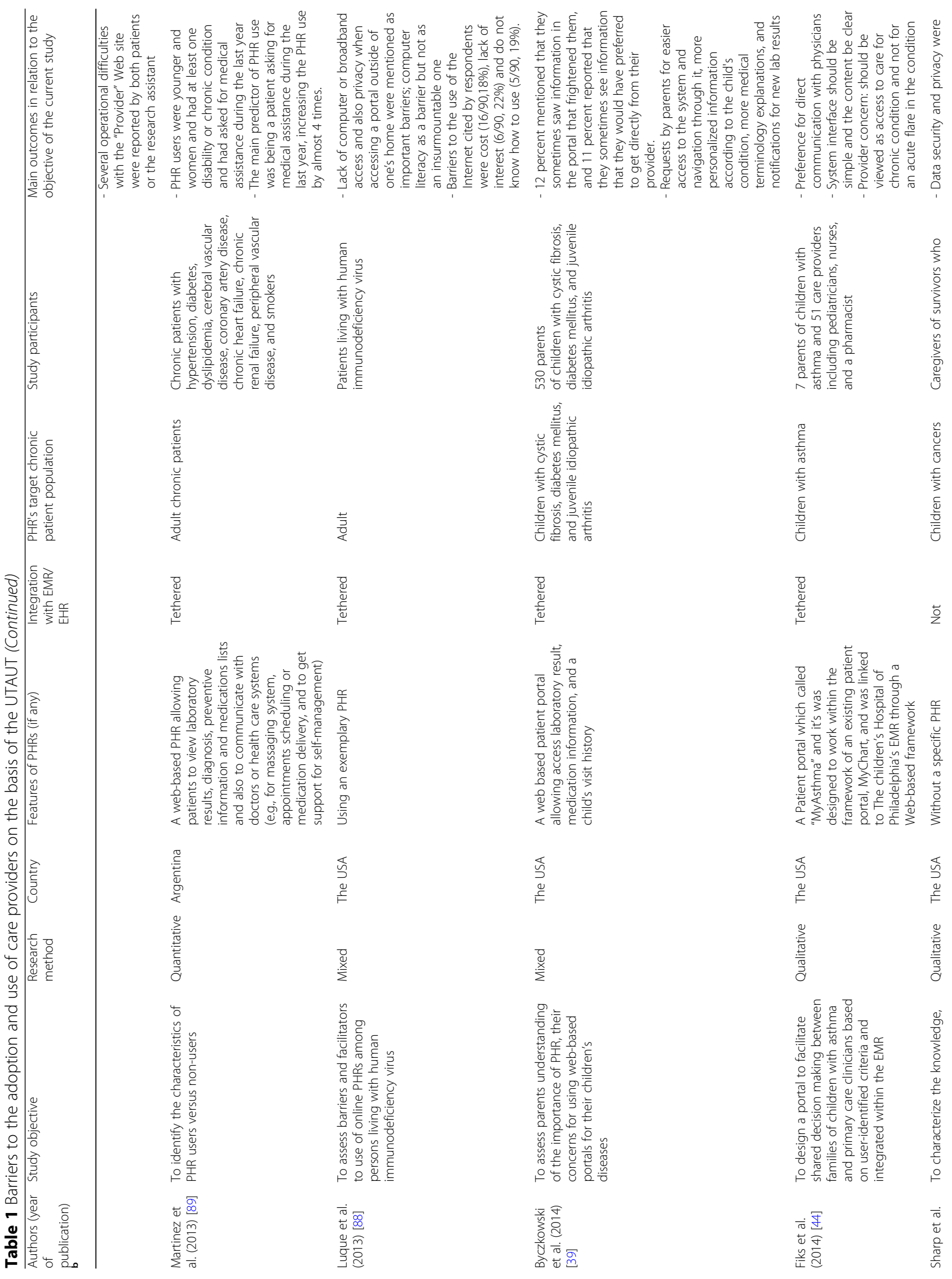




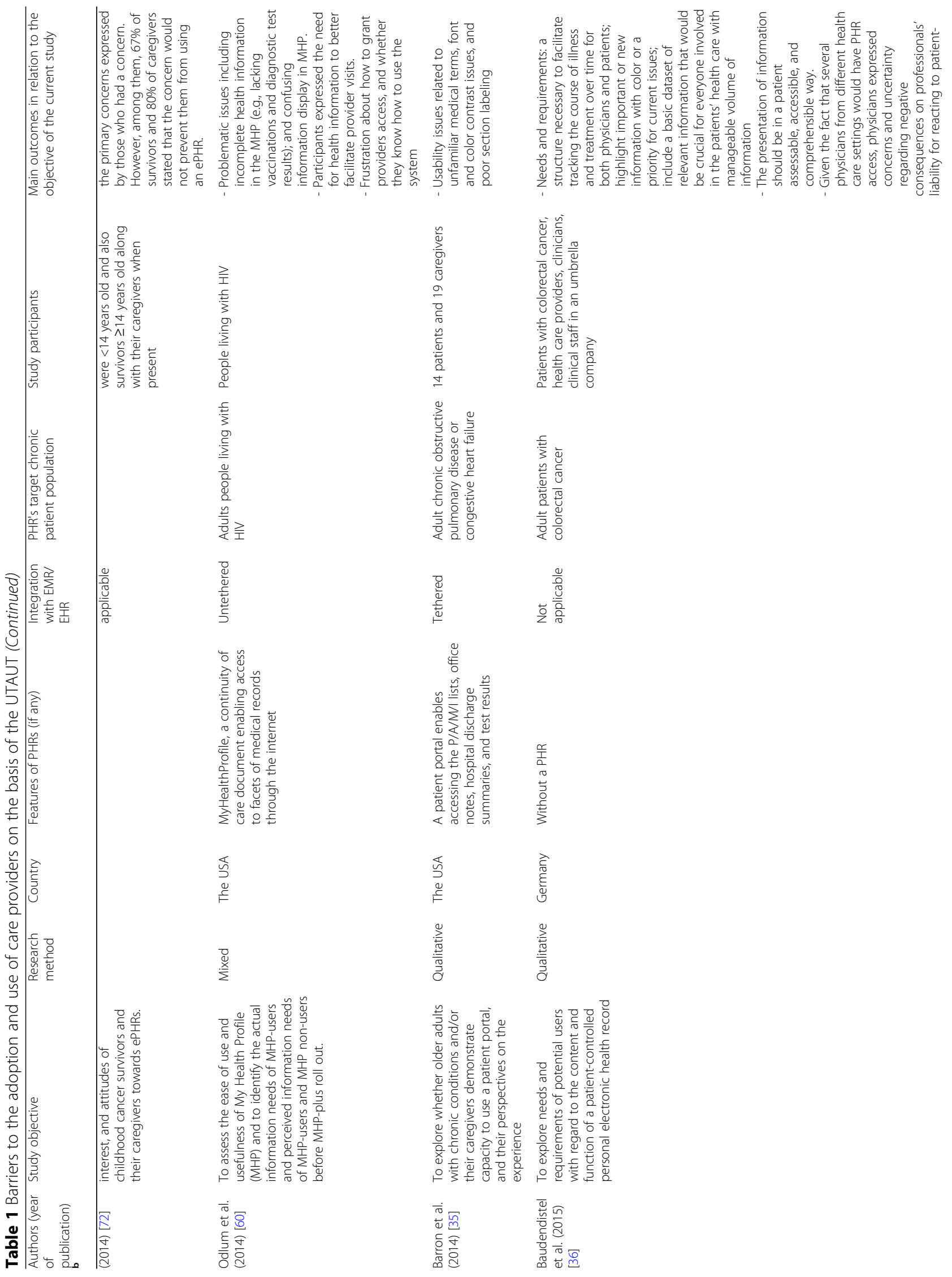




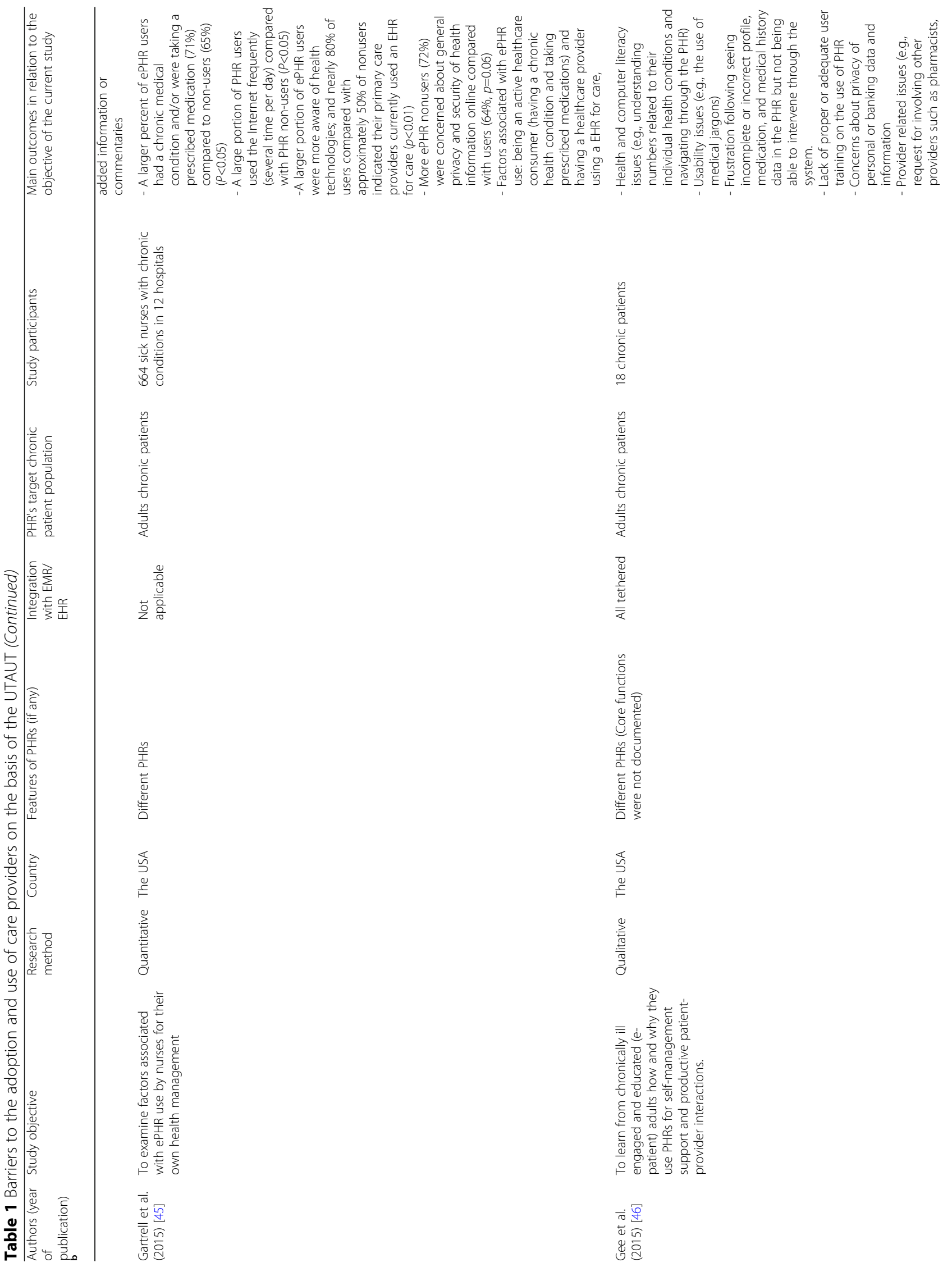




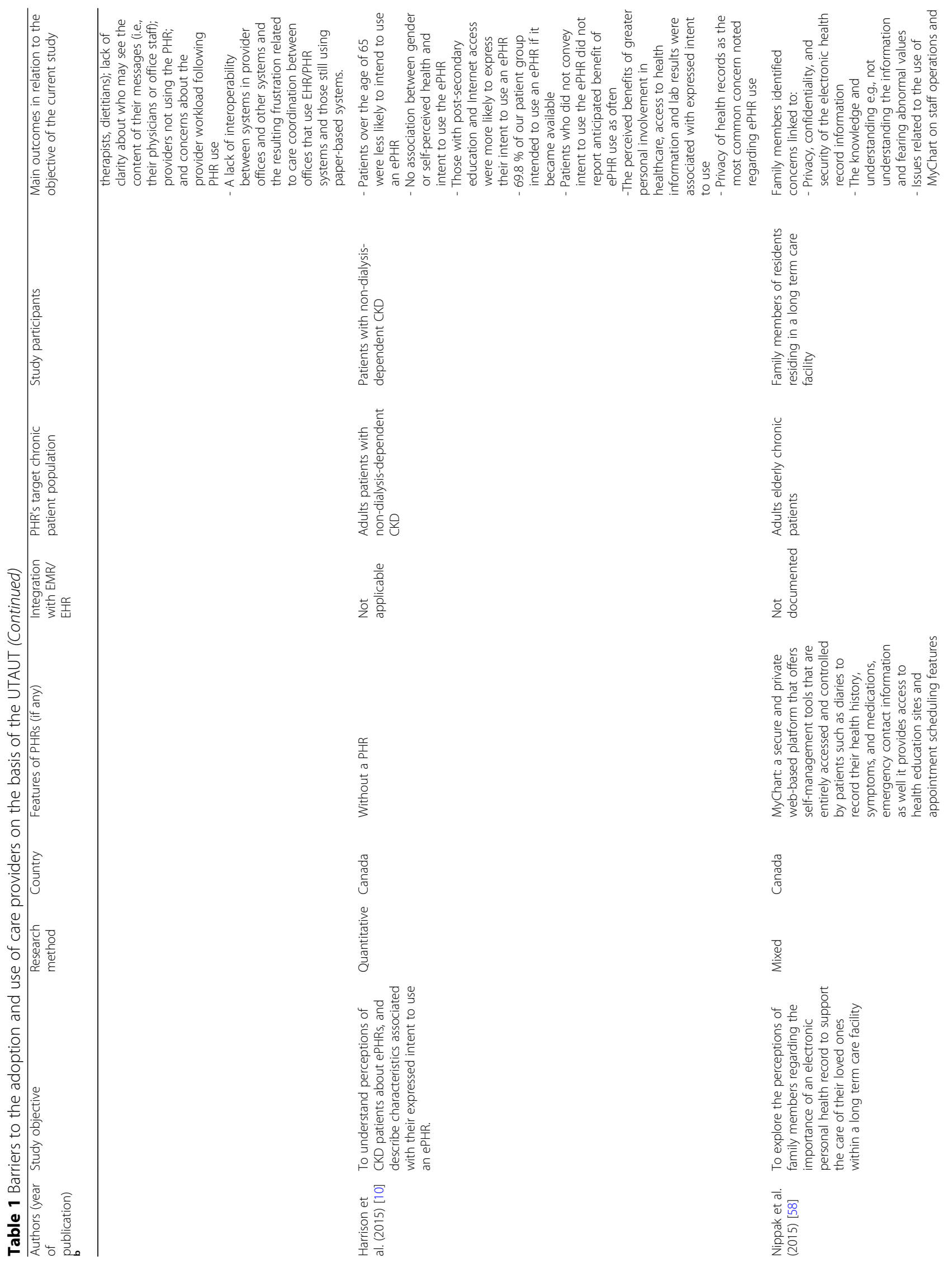




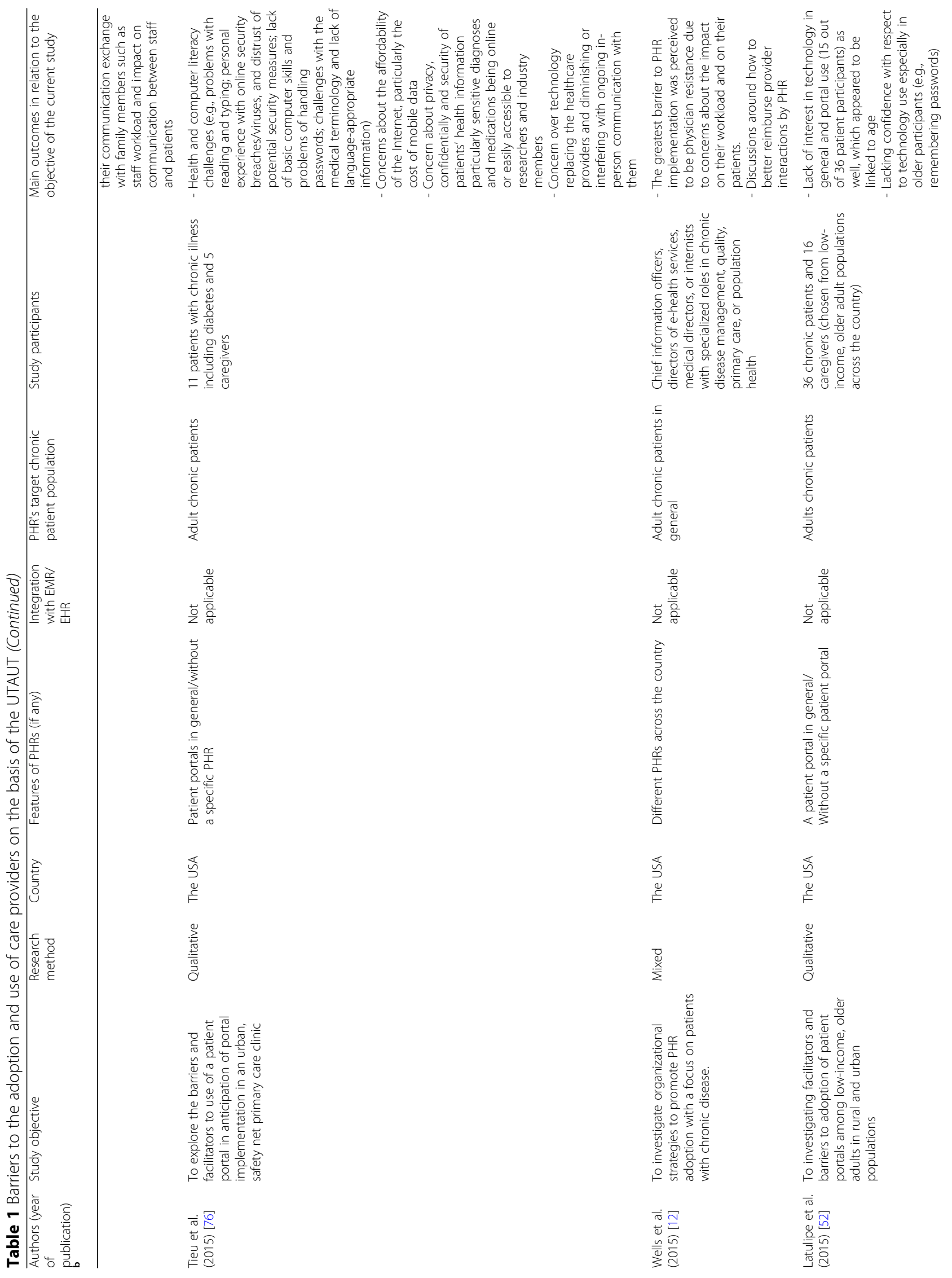




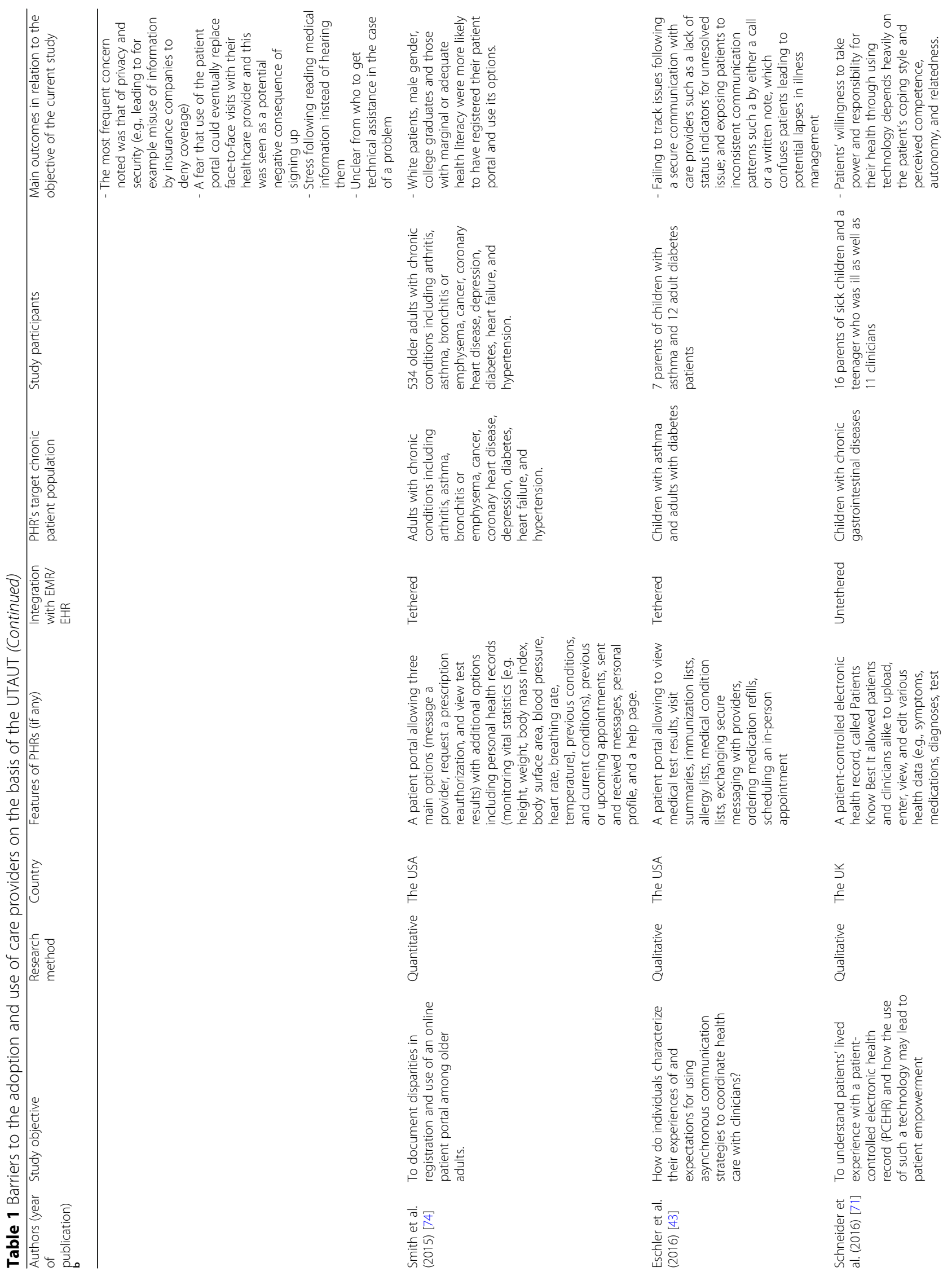




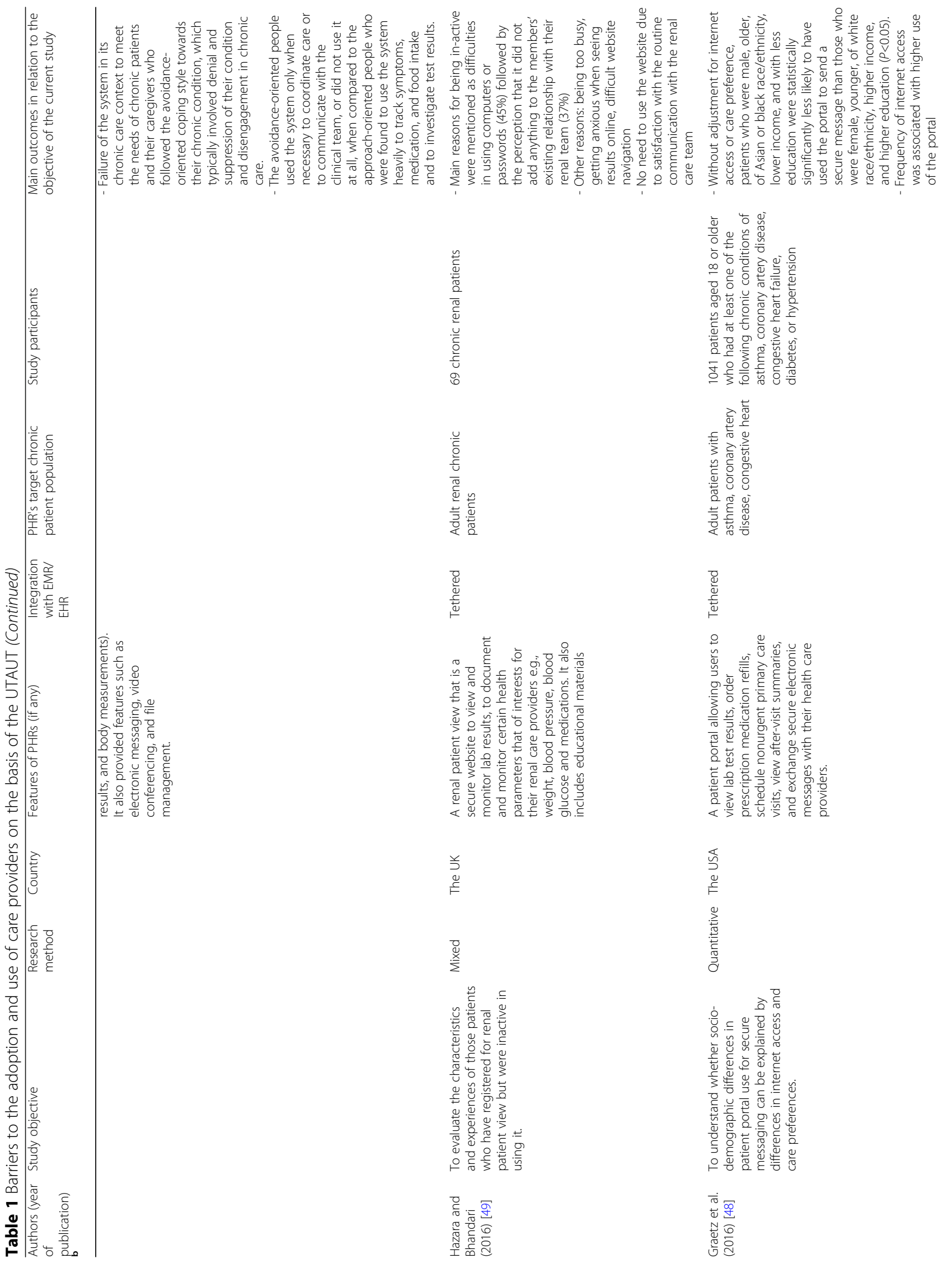




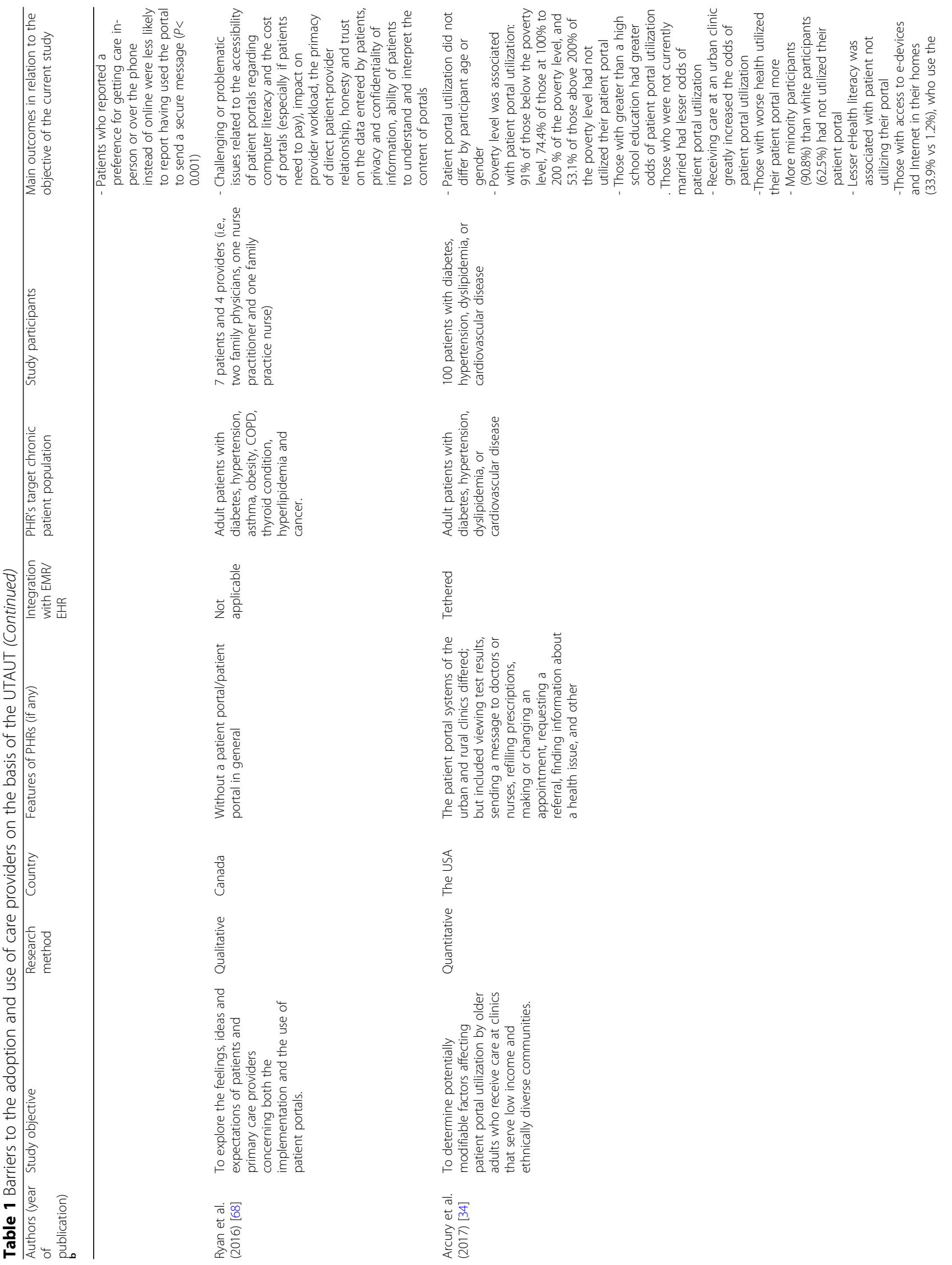




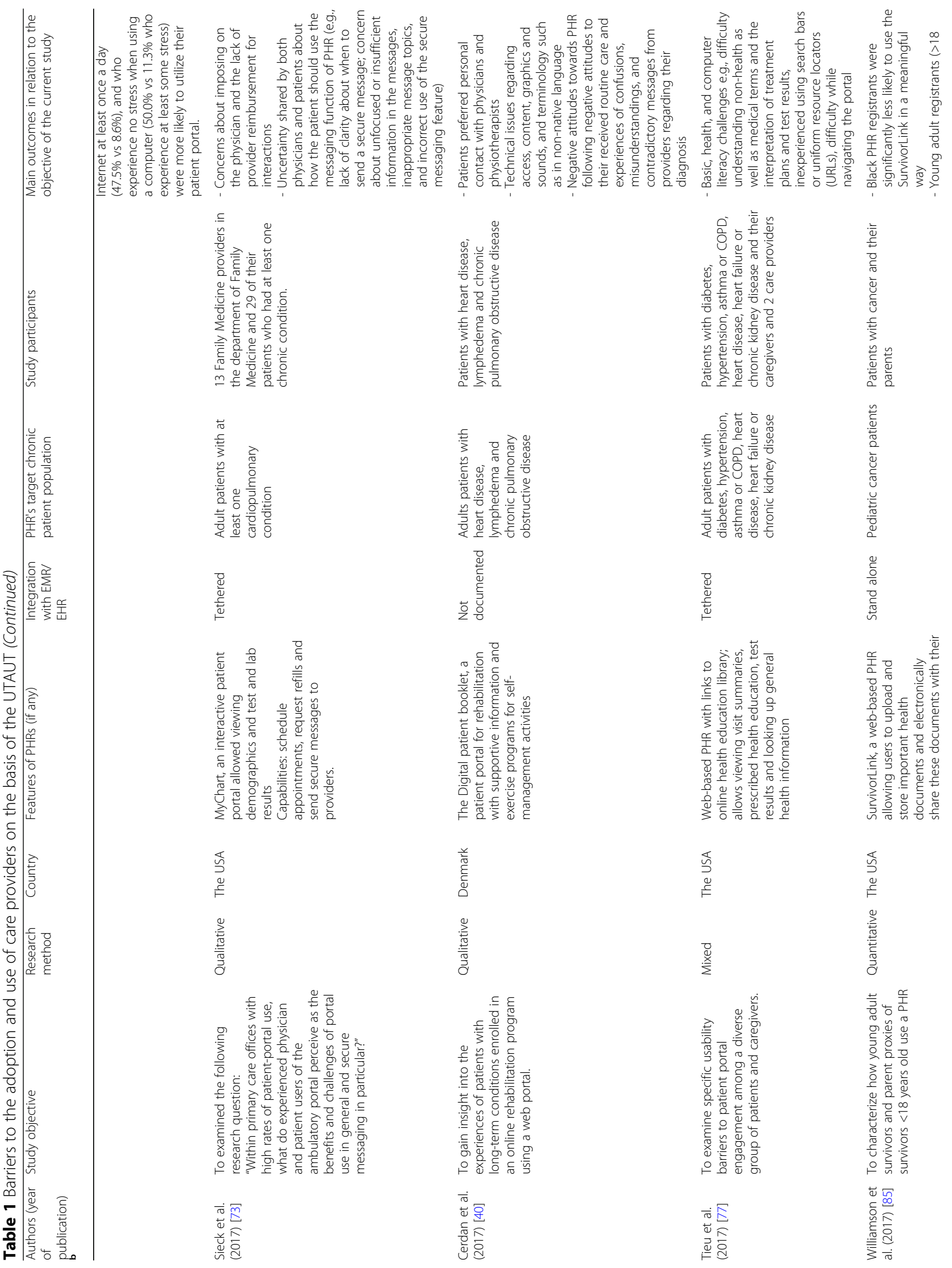




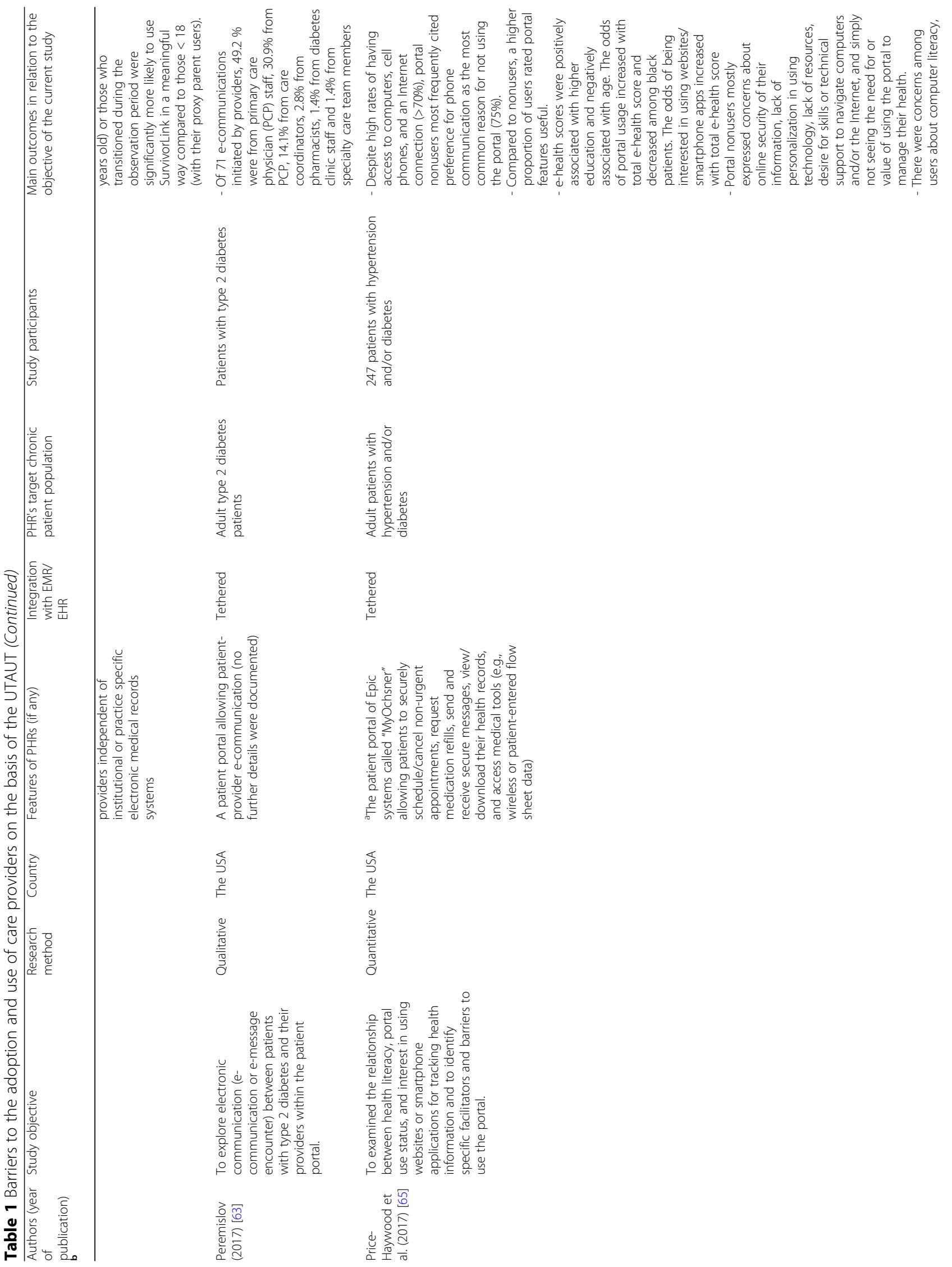




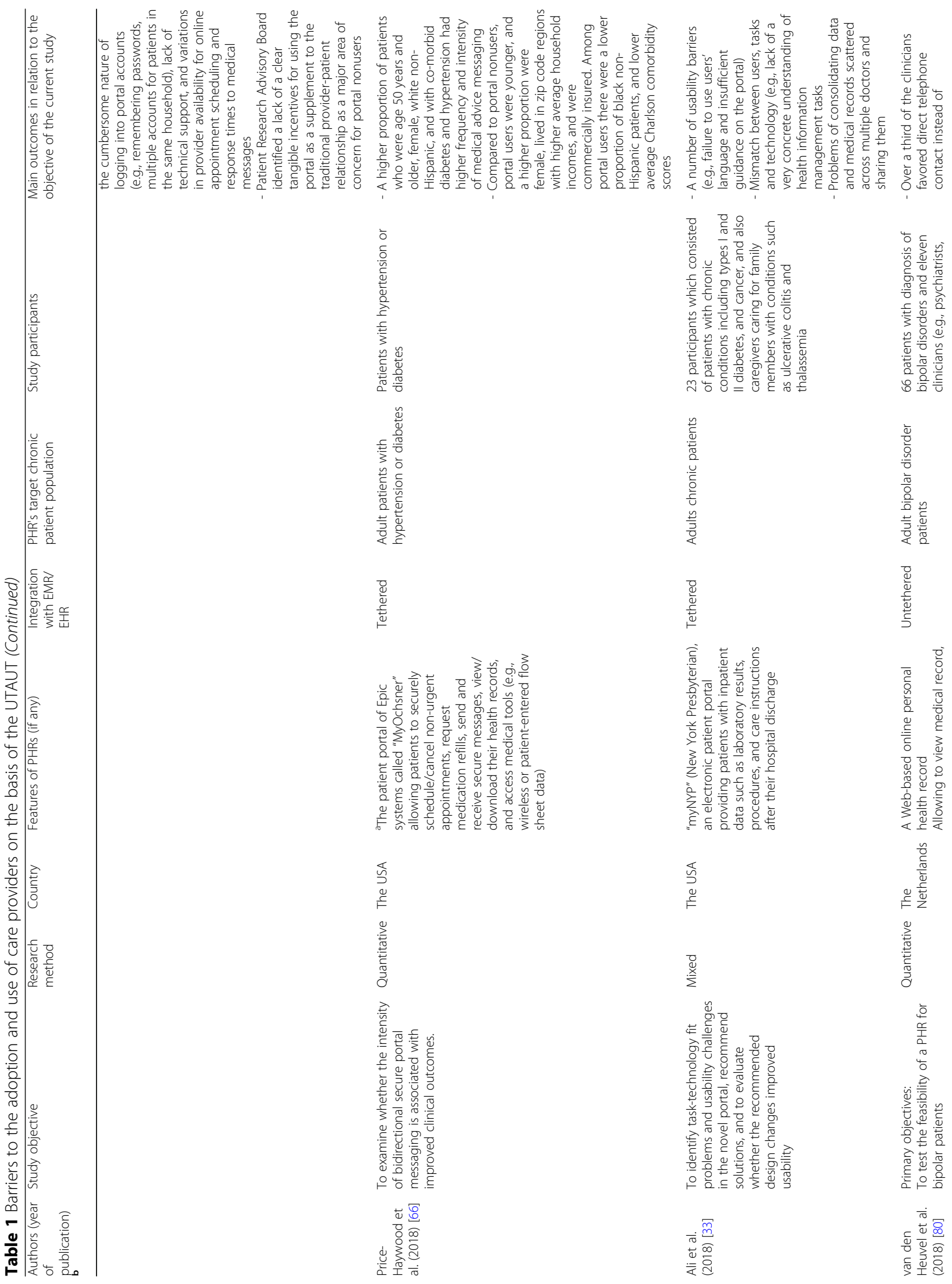




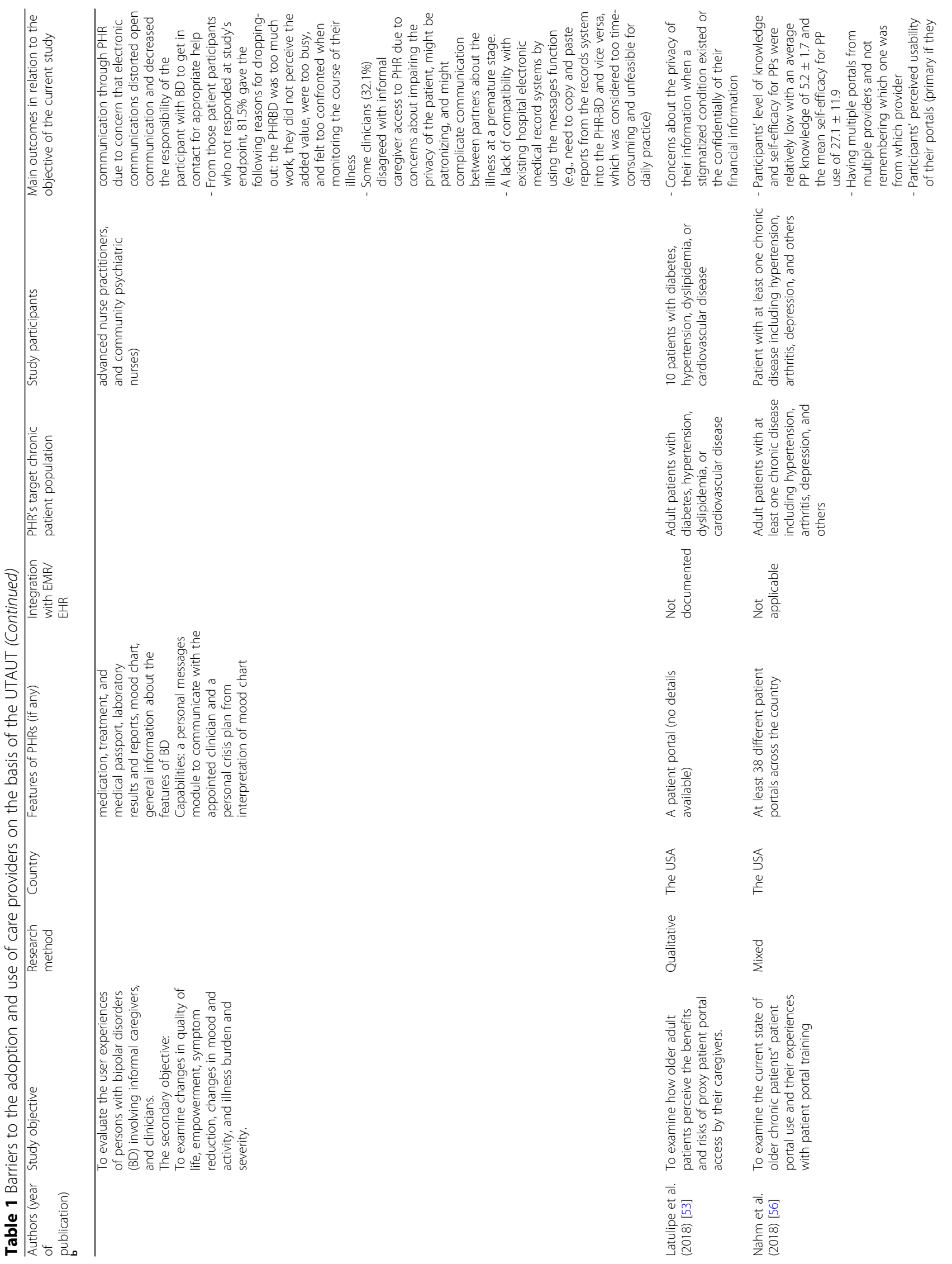




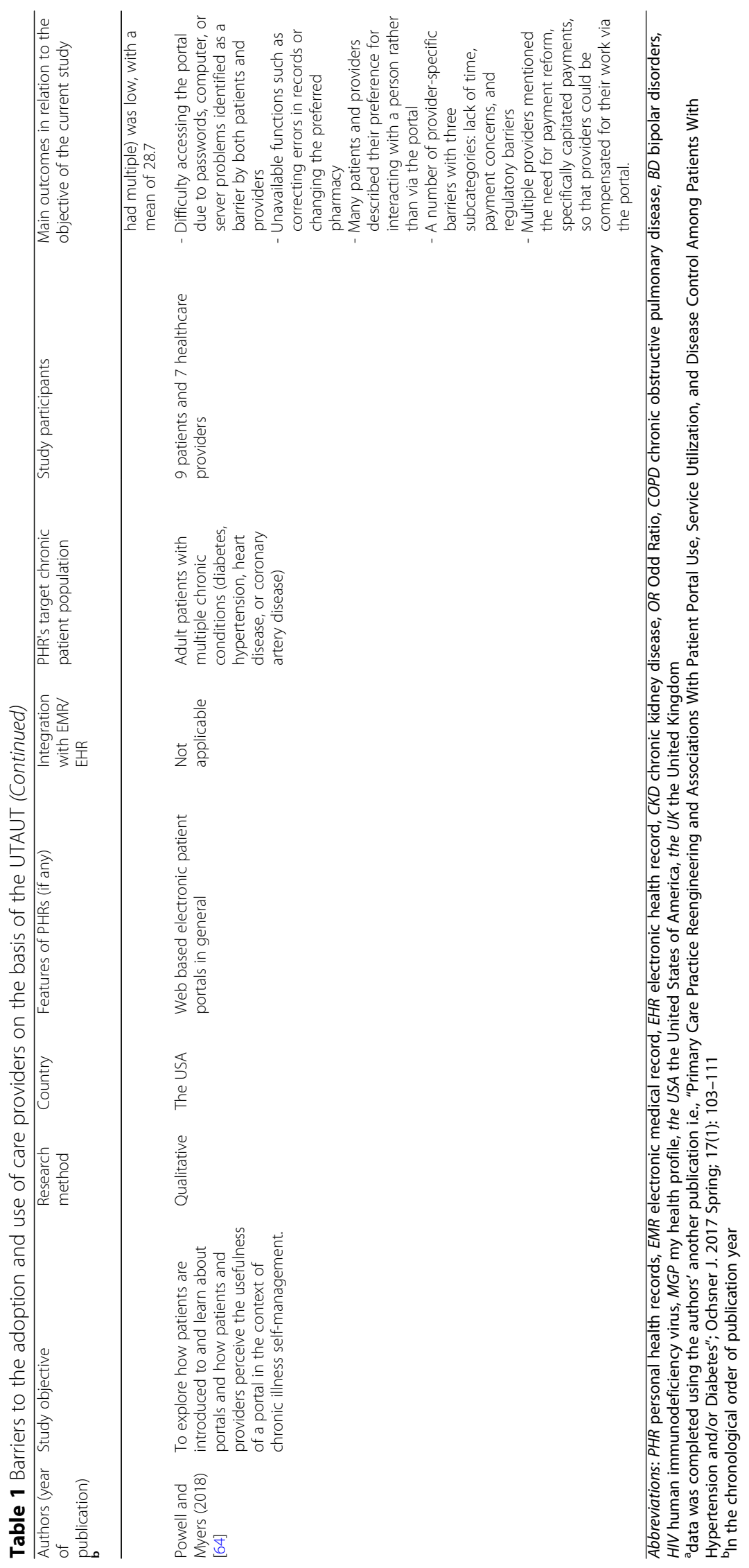


$64,90]$. When comparing with the traditional chronic care, users asked for much easier navigation through ePHRs, access to additional information (e.g., progress notes, outside test results, personalized medication information, and a structure to track the course of treatment) or a customized ePHR based on their specific chronic illness $[36,39,41,44,46,50,60,62,78,80]$.

\section{Perceived complexity}

The difficulty of understanding or navigating an ePHR was one of the most common barriers referred to in the included studies. Use of problematic medical jargon, confusing information display, and unclear presentation of information based on patients' knowledge (e.g., unclear numeral values and unfamiliar medical terms) were only some of the barriers that prevented effective ePHR use [33, 35, 38-41, 46, 49, 50, 59, 60, 68, 76, 78, 79, 82].

\section{Characteristics of chronic disease Attitudes on negotiated collaboration and preferences for self-regulation}

On the one hand, the feeling of having more control over the disease was a reason for limited portal use by patients $[34,59,79]$. Providers also doubted whether patients who were proficient at monitoring their disease were the right group to benefit from ePHRs [79]. On the other hand, being an active healthcare consumer and having a worse or higher proportion of co-morbid conditions and taking more prescribed medications were linked to ePHR use $[34,45,54,66,84,89]$. It was also noted that patients' willingness to take responsibility for their health through ePHR depended on their coping style and perceived competence and autonomy [71]. In a study, patients who "felt too confronted when monitoring the course of their illness" dropped out of an ePHR [80].

\section{The perceived complexity of care}

Based on the task-technology-fit model, a study found instances of mismatches between user mental models and the technology, which manifested primarily as vocabulary misunderstandings, as portal functionality that did not perform as the patient expected, and as requests for clarification and help [33]. They did not have a very concrete understanding of how health information management tasks and processes underlying the ePHR worked.

\section{Characteristics of healthcare settings, providers, and chronic illnesses}

In one study, patients in rural settings were less likely to use ePHRs compared with those in urban settings [34]. However, if patients received care at multiple sites, they were more likely to use ePHRs. Patients acknowledged the need to consolidate data produced by multiple providers and scattered in different locations through ePHRs [33]. A lack of interoperability between ePHRs and EHRs in provider offices was noted in three studies resulting in excess workload and frustration $[46,50,80]$. In a survey of patients from 29 states across the US, with at least 38 different types of portals, $51 \%$ reported having two or more portal accounts creating frustration when it came to patients remembering their names, and managing different portals from different providers [56]. This was a concern in another study, too [65].

Another problem was confusion over who should receive and reply to messages on the provider team i.e., a physician, a nurse, the office staff, or the entire care team; because this would impact the content of patient messages [37, 46, 86]. In another study, patients had unsatisfactory communications with the care team through a portal; for example, they failed to track their health issues in a coherent way [43]. Physicians were concerned about clarity about responsibilities (and potential liabilities) related to responding to patient-added information or commentaries seen by several different clinicians [36]. For the sake of clarity, Table 1 provides a summary of provider-specific barriers.

\section{The methodological quality of the included studies}

Additional file 3 provides the results of the quality check for included studies. There were some quality issues mainly about data collection and interpretation in four studies [5, 87-89]. Because the MMAT discourages excluding studies based on methodological quality, we did include all 60 identified studies in our analysis and report.

\section{Discussion}

Understanding barriers that prevent realizing the ePHR's full benefits is a prerequisite to future work aimed at its optimal use. Our comprehensive review identified 60 relevant studies, which reported barriers to ePHR adoption/use associated with the interacting factors of personal, environmental/medical practice, technology, and chronic disease condition. Our findings expand on those of earlier reviews $[18,19]$ and point out that our knowledge base for this topic is still limited (and one dimensional), with most of the research predominantly focusing on facilitators than barriers and also on barriers at the patient level than those existed beyond the patient level in chronic disease care.

Differences among users of health information technology (HIT) and the implication of their needs and requirements for design and development have recently gained further attention [91-94]. ePHRs are aiming to empower patients and/or caregivers and engage them in collaborative and productive chronic care with health professionals. Failure to acknowledge the characteristics, 
needs, and requirements of all these user groups will lead to the development of unpredictable barriers to ePHR adoption leading to its sub-optimal use. In line with the previous literature, our findings highlight the impact of "digital divide" at the patient level (in terms of age, gender, health, and technology literacy, and socioeconomic status) and several attitudinal factors such as coping styles with a chronic condition (e.g., denial of a condition) and preferences for personal communications with care providers (e.g., preference for direct contact) $[19,95,96]$. Our review also points out that the literature has heavily focused on the elderly, probably because they are disproportionately represented among patients with chronic diseases. Thus, it is plausible that the barriers faced by the younger and also middle-aged $(<50$ years old) chronic patients would be underrecognized and ePHR use in these groups may fall behind. This is particularly important because of the increasing prevalence of chronic diseases such as diabetes in these age groups. These groups increasingly represent users with higher educational levels and technology literacy (with higher needs and expectations), compared with that of the elderly, introducing a niche market for ePHRs and a unique opportunity to tap into their potential. Moreover, while providing the care for young chronic patients (e.g., between 10 and 19 years old), these adolescent users are a different user group when compared to their parent caregivers and this becomes more important especially when these patients transit from pediatric care to receive adulthood care. Thus, their needs and requirements for an effective and useful ePHR should be given much attention helping a smooth and safe care transition. Such an approach will, to a great extent, make sure that using an ePHR becomes an enriching experience for both the adolescents and those involved in their care.

Most of the healthcare systems have important constraints in terms of human resources shortages, inadequate infrastructure, and insufficient finances, which require mindful management to operate and maximize efficiency [97]. ePHRs have the potentials to do so by facilitating self-care and virtual visits. However, in the context of ePHR use, the responsibilities of patients and providers are changed in many ways. For example, they need to make sure that the data available in different locations are accurate, integrated, and updated [3]. This is important particularly because data about chronic care is scattered throughout different EHRs that do not speak together; and then, the task of data integration is informally delegated to patients. ePHRs can be used meaningfully if they are implemented as a component (i.e., a tool for selfmanagement) of comprehensive care models developed for chronic care (such as the Wagner's Chronic Care Model [98]). If such models are implemented and proper links are made among their components (i.e., self- management, clinical information systems, disease registries, and decision support systems), patients are freed from extra responsibilities and can focus on productive "self-management" through an ongoing collaborative process with their providers via ePHRs. Therefore, as the adoption of ePHRs are very related to the adoption of EHRs, the barriers related to EHRs in the first place and then the interoperability between these two should adequately be addressed [17, 21, 27]. For example, providers should consider ePHRs' potentials and their fit within the information infrastructure of their practice when they commence investing in EHRs and choosing their vendors. This becomes especially important after changes that the outbreak of the novel coronavirus disease has brought up to the current and future practice in terms of managing virtual visits. Unfortunately, discussion on such issues has been underrepresented in the identified studies, which should be taken into account in future research.

Our review shows that the barriers related to the providers and the organization of chronic care have not fully been studied despite their importance (studied by only 8 studies). The lack of provider interest and even their resistance to adopting ePHRs are important $[3,12$, $21,99]$. Provider concerns about the impacts on workload, professional/legal liabilities, relationships with patients, and the lack of reimbursements should be fully addressed [15, 21, 100, 101]. Moreover, their involvement in ePHR use has not been given full attention as it deserves. In a review of 19 ePHRs, only half had enabled user actions taken by physicians [17]. Providers can act as an effective catalyst in this regard by practicing their social influence on patients [102]. Scholars have highlighted that without involving providers in ePHR's design, implementation, and application and without addressing their barriers, efforts for widespread ePHR adoption/use would be in vain $[3,103,104]$. Therefore, it will be insightful if future studies explore in more depth provider issues and how they can further be engaged with this emerging technology in chronic care.

Functionalities of ePHRs that provide solutions for personalized needs and requirements of chronic patients have important implications for their adoption and use, as also emerged in our review [17, 19, 73, 90, 105]. One review suggested that features such as access to personal health data and general health information, communicating with providers and support groups, and receiving personal decision support were linked to empirical evidence of benefits from ePHR-enabled self-management [19]. Yet, no ePHR in that review described a platform for all those features. Furthermore, the necessity for measures to ensure the privacy and confidentiality in record transactions and communication through ePHRs was a serious concern voiced by clinical directors and health information technology leaders, besides patients 
$[10,12,45,47,52,58,65,68,72,76,78,80]$. The relevancy of this concern has also been highlighted elsewhere $[20,21,27,95,106]$. Reviewing privacy policies of 24 ePHRs showed that such concerns are very relevant and that compliance with privacy standards and regulations were generally low [14]. It has been recommended that institutions should assemble governance groups to develop policies regarding security, privacy, and confidentiality of records to assure ePHR users on preserving their rights [12].

\section{Strengths and weaknesses of our review}

To our knowledge, no study to date has analyzed ePHR studies exclusively concerning barriers to its adoption and use in chronic care. Nevertheless, our review has several limitations. First of all, we only included studies published in English. Second, facilitators and barriers to the adoption of technology is a complex concept without an agreed-upon research methodology. It is plausible that many of the discussions about these core concepts have appeared only in non-peer-reviewed or research publications such as white papers, perspectives, editorials, etc. The findings of our systematic review are confined by the content of included articles, and hence may not well reflect a proper balance of what is known on the topic. Such reviews, however, point out the gaps and direct future studies. Third, ePHRs are an evolving technology with new features and functionalities and so is their position in chronic care. Therefore, the barriers identified in this review are possibly not generalizable to all patient populations or different implementation strategies and healthcare systems. For example, a majority of studies are from the US and therefore a Western viewpoint is predominant here. Therefore, it should be born in mind that the barriers faced by users might be different in different healthcare contexts.

\section{Conclusion}

If we are to reap the full benefits of ePHRs in chronic care, we ought to understand the unique characteristics of this type of care and the barriers and challenges that ePHR users face in adoption and sustained use, in the first place. This knowledge should be used to make ePHR functionalities that fit in these unique characteristics well. Future research must aim at identifying the barriers experienced especially by younger chronic patients and their requirements and expectations, and also those barriers faced by care providers all beyond the patient level. A deeper understating of these barriers will reveal opportunities that if addressed in the design, development, and implementation can lead to the enhanced use of ePHRs.

\section{Supplementary information}

Supplementary information accompanies this paper at https://doi.org/10. 1186/s12911-020-01159-1.

Additional file 1: The search strategy in the electronic databases used in our study.

Additional file 2: The main reasons for exclusion of articles.

Additional file 3: Quality of included studies by the MMAT tool.

Additional file 4. Studies providing information on barriers to PHR adoption and use in chronic care.

\begin{abstract}
Abbreviations
ePHRs: Electronic Personal Health Records; CINAHL: Cumulative Index to Nursing and Allied Health Literature; IEEE: Institute of Electrical and

Electronics Engineers; HITECH: Health Information Technology for Economic and Clinical Health Act; EHRs: Electronic Health Records; US: The United States; PRISMA: Preferred Reporting Items for Systematic reviews and MetaAnalyses; MMAT: Mixed Methods Appraisal Tool; PHRAM: Personal Health Records Adoption Model; UTAUT: Unified Theory of Acceptance and Use of Technology; HIT: Health Information Technology; UUMS: Urmia University of Medical Sciences
\end{abstract}

\section{Acknowledgement}

Not applicable

\section{Summary table}

- Barriers to ePHR adoption/use, with a special focus in chronic care, has not been well described and understood

- Addressing barriers for ePHR adoption/use in chronic care should cross the boundary of patient-level barriers

- Barriers at the provider and healthcare organization levels should be understood and addressed, thoroughly

- ePHRs should fit in the structure of "chronic care models" developed for improving chronic care

\section{Authors' contributions}

ZN, ET, MCK and HP designed the study and the search strategy. ET conducted the systematic search. ZN, ET and MCK screened the titles and abstracts and reviewed full texts of articles and extracted data. ZN wrote the early version and revised it according to ET, MCK, AG and HP' comments. ET, MCK, AG and HP contributed in the interpretation of the results. HP conducted the quality check of the included studies. ZN, ET, MCK, AG and $\mathrm{HP}$ read and approved the final version.

\section{Funding}

This study was part of a Master of Science thesis (grant number 2952) in medical informatics domain of the second author funded partially by Urmia University of Medical Sciences (UUMS). It did not receive any specific grant from funding agencies in the public, commercial, or not-for-profit sectors. UUMS had no role in the design of the study and collection, analysis, and interpretation of data as well as in writing the manuscript

\section{Availability of data and materials}

All data generated or analyzed during this systematic review are included in this published article [and its supplementary information files].

\section{Ethics approval and consent to participate}

According to our institution's research ethics policies, a review study did not require an ethics approval or any consent for participation in the study.

Consent for publication

This study does not include any confidential information. Then, consent for publication is not applicable.

Competing interests

None 


\section{Author details}

${ }^{1}$ Nephrology and Kidney Transplant Research Center, Urmia University of Medical Sciences, Urmia, Iran. ${ }^{2}$ Department of Health Information Technology, Urmia University of Medical Sciences, Urmia, Iran. ${ }^{3}$ Student Research Committee, Urmia University of Medical Sciences, Urmia, Iran. ${ }^{4}$ Office for Disease Registry and Health Outcomes, Urmia University of Medical Sciences, Urmia, Iran. ${ }^{5}$ Centre for Health Systems and Safety Research, Australian Institute of Health Innovation, Macquarie University, Sydney, Australia. ${ }^{6}$ Patient Safety Research Center, Urmia University of Medical Sciences, Urmia, Iran. ${ }^{7}$ Erasmus School of Health Policy \& Management (ESHPM), Erasmus University Rotterdam, Rotterdam, The Netherlands.

Received: 23 January 2020 Accepted: 22 June 2020

Published online: 08 July 2020

\section{References}

1. Ausili D, Masotto M, Dall'Ora C, Salvini L, Di Mauro S. A literature review on self-care of chronic illness: definition, assessment and related outcomes. Professioni infermieristiche. 2014;67(3):180-9 PubMed PMID: 25392031

2. Kennedy A, Rogers A, Bower P. Support for self care for patients with chronic disease. Bmj. 2007;335(7627):968-70 PubMed PMID: 17991978. Pubmed Central PMCID: 2071971

3. Tang PC, Ash JS, Bates DW, Overhage JM, Sands DZ. Personal health records: definitions, benefits, and strategies for overcoming barriers to adoption. J Am Med Inform Assoc. 2006;13(2):121-6 PubMed PMID: 16357345. Pubmed Central PMCID: 1447551

4. Tenforde M, Jain A, Hickner J. The value of personal health records for chronic disease management: what do we know? Family Med. 2011;43(5): 351-4 PubMed PMID: 21557106.

5. Lober WB, Zierler B, Herbaugh A, Shinstrom SE, Stolyar A, Kim EH, et al. Barriers to the use of a personal health record by an elderly population, AMIA Annual Symposium proceedings AMIA Symposium; 2006. p. 514-8. PubMed PMID: 17238394. Pubmed Central PMCID: 1839577.

6. Keith McInnes D, Shimada SL, Rao SR, Quill A, Duggal M, Gifford AL, et al. Personal health record use and its association with antiretroviral adherence: survey and medical record data from 1871 US veterans infected with HIV. AIDS Behav. 2013;17(9):3091-100 PubMed PMID: 23334359.

7. Martinez Nicolas I, Le Cook B, Flores M, Del Olmo RM, Hernandez Rodriguez C, Llamas Sillero P, et al. The impact of a comprehensive electronic patient portal on the health service use: an interrupted time-series analysis. Eur J Public Health. 2019;29(3):413-18.

8. Sorondo B, Allen A, Fathima S, Bayleran J, Sabbagh I. Patient Portal as a Tool for Enhancing Patient Experience and Improving Quality of Care in Primary Care Practices. Egems. 2016;4(1):1262 PubMed PMID: 28203611. Pubmed Central PMCID: 5302860

9. Pipersburgh J. The push to increase the use of EHR technology by hospitals and physicians in the United States through the HITECH Act and the Medicare incentive program. Journal of health care finance. 2011;38(2):5478 PubMed PMID: 22372032.

10. Harrison TG, Wick J, Ahmed SB, Jun M, Manns BJ, Quinn RR, et al. Patients with chronic kidney disease and their intent to use electronic personal health records. Can J Kidney Health Dis. 2015;2:23 PubMed PMID: 26075082. Pubmed Central PMCID: PMC4465011. Epub 2015/06/16. eng.

11. Kruse CS, Argueta DA, Lopez L, Nair A. Patient and provider attitudes toward the use of patient portals for the management of chronic disease: a systematic review. Journal of medical Internet research. 2015;17(2):e40 PubMed PMID: 25707035. Pubmed Central PMCID: 4376181.

12. Wells S, Rozenblum R, Park A, Dunn M, Bates DW. Organizational strategies for promoting patient and provider uptake of personal health records. J Am Med Inform Assoc. 2015;22(1):213-22 PubMed PMID: 25326601. Pubmed Central PMCID: 4433381

13. Adler-Milstein J, DesRoches CM, Furukawa MF, Worzala C, Charles D, Kralovec $P$, et al. More than half of US hospitals have at least a basic EHR, but stage 2 criteria remain challenging for most. Health Aff. 2014;33(9): 1664-71 PubMed PMID: 25104826.

14. Carrion Senor I, Fernandez-Aleman JL, Toval A. Are personal health records safe? A review of free web-accessible personal health record privacy policies. J Med Internet Res. 2012;14(4):e114 PubMed PMID: 22917868 Pubmed Central PMCID: 3510685.
15. Lester M, Boateng S, Studeny J, Coustasse A. Personal Health Records: Beneficial or Burdensome for Patients and Healthcare Providers? Perspect Health Inf Manag. 2016;13:1h PubMed PMID: 27134613. Pubmed Central PMCID: 4832132

16. Greenhalgh T, Hinder S, Stramer K, Bratan T, Russell J. Adoption, nonadoption, and abandonment of a personal electronic health record: case study of HealthSpace. Bmj. 2010;341:c5814 PubMed PMID: 21081595. Pubmed Central PMCID: 2982892

17. Ross J, Stevenson F, Lau R, Murray E. Factors that influence the implementation of e-health: a systematic review of systematic reviews (an update). Implement Sci. 2016;11(1):146 PubMed PMID: 27782832. Pubmed Central PMCID: 5080780

18. Powell KR. Patient-Perceived Facilitators of and Barriers to Electronic Portal Use: A Systematic Review. Comput Inform Nurs. 2017;35(11):565-73 PubMed PMID: 28723832

19. Showell C. Barriers to the use of personal health records by patients: a structured review. PeerJ. 2017:5:e3268 PubMed PMID: 28462058. Pubmed Central PMCID: 5410160

20. Wildenbos GA, Peute L, Jaspers M. Facilitators and Barriers of Electronic Health Record Patient Portal Adoption by Older Adults: A Literature Study. Stud Health Technol Inform. 2017;235:308-12 PubMed PMID: 28423804.

21. Hargreaves JS. Will electronic personal health records benefit providers and patients in rural America? Telemed J E-health. 2010;16(2):167-76 PubMed PMID: 20082592

22. Vance B, Tomblin B, Studeny J, Coustasse A. Benefits and barriers for adoption of personal health records. Chicago: the 51st Annual Midwest Business Administration Association International Conference; 2015. p. 2015.

23. Moher D, Liberati A, Tetzlaff J, Altman DG, Group P. Preferred reporting items for systematic reviews and meta-analyses: the PRISMA statement. PLoS Med. 2009;6(7):e1000097 PubMed PMID: 19621072. Pubmed Central PMCID: 2707599

24. Thompson MJ, Reilly JD, Valdez RS. Work system barriers to patient, provider, and caregiver use of personal health records: A systematic review. Appl Ergonom. 2016;54:218-42 PubMed PMID: 26851482.

25. Archer N, Fevrier-Thomas U, Lokker C, McKibbon KA, Straus SE. Personal health records: a scoping review. J Am Med Inform Assoc. 2011;18(4):515-22 PubMed PMID: 21672914. Pubmed Central PMCID: 3128401.

26. Ko H, Turner $\mathrm{T}$, Jones $\mathrm{C}$, Hill C. Patient-held medical records for patients with chronic disease: a systematic review. Qual Safety Health Care. 2010; 19(5):e41 PubMed PMID: 20511601

27. Roehrs A, da Costa CA, Righi RD, de Oliveira KS. Personal Health Records: A Systematic Literature Review. J Med Internet Res. 2017;19(1):e13 PubMed PMID: 28062391. Pubmed Central PMCID: 5251169.

28. Bouayad L, lalynytchev A, Padmanabhan B. Patient Health Record Systems Scope and Functionalities: Literature Review and Future Directions. J Med Internet Res. 2017;19(11):e388 PubMed PMID: 29141839. Pubmed Central PMCID: 5707430

29. Coughlin SS, Prochaska JJ, Williams LB, Besenyi GM, Heboyan V, Goggans DS, et al. Patient web portals, disease management, and primary prevention. Risk Manag Healthcare Policy. 2017;10:33-40 PubMed PMID: 28435342. Pubmed Central PMCID. 5391175

30. Hong QN, Pluye P, Fabregues S, Bartlett G, Boardman F, Cargo M, et al. Improving the content validity of the mixed methods appraisal tool: a modified e-Delphi study. J Clin Epidemiol. 2019;111:49-59.e1 PubMed PMID: 30905698.

31. Logue MD, Effken JA. Modeling factors that influence personal health records adoption. Comput Inform Nurs. 2012;30(7):354-62 PubMed PMID: 22525046.

32. Venkatesh V, Morris MG, Davis GB, Davis FD. User Acceptance of Information Technology: Toward a Unified View. MIS Quart. 2003;27(3):425-78.

33. Ali SB, Romero J, Morrison K, Hafeez B, Ancker JS. Focus Section Health IT Usability: Applying a Task-Technology Fit Model to Adapt an Electronic Patient Portal for Patient Work. Appl Clin Inform. 2018;9(1):174-84 PubMed PMID: 29539648. Pubmed Central PMCID: PMC5851788. Epub 2018/03/15. eng.

34. Arcury TA, Quandt SA, Sandberg JC, Miller DP Jr, Latulipe C, Leng X, et al. Patient Portal Utilization Among Ethnically Diverse Low Income Older Adults: Observational Study. JMIR Med Inform. 2017;5(4):e47 PubMed PMID: 29138129. Pubmed Central PMCID: 5705857.

35. Barron J, Bedra M, Wood J, Finkelstein J. Exploring three perspectives on feasibility of a patient portal for older adults. Stud Health Technol Inform. 2014;202:181-4 PubMed PMID: 25000046. Epub 2014/07/08. eng.

36. Baudendistel I, Winkler E, Kamradt M, Langst G, Eckrich F, Heinze O, et al. Personal electronic health records: understanding user requirements and 
needs in chronic cancer care. J Med Internet Res. 2015;17(5):e121 PubMed PMID: 25998006. Pubmed Central PMCID: PMC4468571. Epub 2015/05/23. eng.

37. Britto MT, Hesse EA, Kamdar OJ, Munafo JK. Parents' perceptions of a patient portal for managing their child's chronic illness. J Pediatr. 2013; 163(1):280-1.e1-2 PubMed PMID: 23541773. Epub 2013/04/02. eng.

38. Britto MT, Jimison HB, Munafo JK, Wissman J, Rogers ML, Hersh W. Usability testing finds problems for novice users of pediatric portals. J Am Med Inform Assoc. 2009;16(5):660-9 PubMed PMID: 19567793. Pubmed Central PMCID: PMC2744717. Epub 2009/07/02. eng.

39. Byczkowski TL, Munafo JK, Britto MT. Family perceptions of the usability and value of chronic disease web-based patient portals. Health Inform J. 2014; 20(2):151-62 PubMed PMID: 24056751. Epub 2013/09/24. eng.

40. Cerdan J, Catalan-Matamoros D, Berg SW. Online communication in a rehabilitation setting: Experiences of patients with chronic conditions using a web portal in Denmark. Patient Educ Couns. 2017;100(12):2283-9 PubMed PMID: 28698033. Epub 2017/07/13. eng.

41. Day K, Gu Y. Influencing factors for adopting personal health record (PHR). Stud Health Technol Inform. 2012;178:39-44 PubMed PMID: 22797017. Epub 2012/07/17. eng.

42. Emani S, Yamin CK, Peters E, Karson AS, Lipsitz SR, Wald JS, et al. Patient perceptions of a personal health record: a test of the diffusion of innovation model. J Med Internet Res. 2012;14(6):e150 PubMed PMID: 23128775. Pubmed Central PMCID: 3517342

43. Eschler J, Meas PL, Lozano P, McClure JB, Ralston JD, Pratt W. Integrating the patient portal into the health management work ecosystem: user acceptance of a novel prototype. AMIA Annu Symp Proc. 2016;2016:541-50 PubMed PMID: 28269850. Pubmed Central PMCID: 5333335

44. Fiks AGMDM, Mayne SMHS, Karavite DJMSI, DeBartolo EBS, Grundmeier RWMD. A Shared e-Decision Support Portal for Pediatric Asthma. J Ambul Care Manag. 2014;37(2):120-6.

45. Gartrell K, Storr CL, Trinkoff AM, Wilson ML, Gurses AP. Electronic personal health record use among registered nurses. Nursing outlook. 2015;63(3): 278-87 PubMed PMID: 25982768. Pubmed Central PMCID: 4438260.

46. Gee PM, Paterniti DA, Ward D, Soederberg Miller LM. e-Patients Perceptions of Using Personal Health Records for Self-management Support of Chronic IIIness. Comput Inform Nurs. 2015;33(6):229-37 PubMed PMID: 25899440.

47. Goel MS, Brown TL, Williams A, Cooper AJ, Hasnain-Wynia R, Baker DW. Patient reported barriers to enrolling in a patient portal. J Am Med Inform Assoc. 2011;18(Suppl 1):i8-12 PubMed PMID: 22071530. Pubmed Central PMCID: PMC3241181. Epub 2011/11/11. eng.

48. Graetz I, Gordon N, Fung V, Hamity C, Reed ME. The Digital Divide and Patient Portals: Internet Access Explained Differences in Patient Portal Use for Secure Messaging by Age, Race, and Income. Med Care. 2016;54(8):7729 PubMed PMID: 27314262. Epub 2016/06/18. eng.

49. Hazara AM, Bhandari S. Barriers to patient participation in a selfmanagement and education website Renal PatientView: A questionnairebased study of inactive users. Int J Med Inform. 2016;87:10-4 PubMed PMID: 26806707. Epub 2016/01/26. eng.

50. Hess R, Bryce CL, Paone S, Fischer G, McTique KM, Olshansky E, et al. Exploring challenges and potentials of personal health records in diabetes self-management: implementation and initial assessment. Telemed J Ehealth. 2007;13(5):509-17 PubMed PMID: 17999613.

51. Kim EH, Stolyar A, Lober WB, Herbaugh AL, Shinstrom SE, Zierler BK, et al. Challenges to using an electronic personal health record by a low-income elderly population. J Med Internet Res. 2009;11(4):e44 PubMed PMID: 19861298. Pubmed Central PMCID: 2802566.

52. Latulipe C, Gatto A, Nguyen HT, Miller DP, Quandt SA, Bertoni AG, et al. Design Considerations for Patient Portal Adoption by Low-Income, Older Adults. Proc SIGCHI Conf Human Factors Comput Syst CHI Conf. 2015;2015: 3859-68 PubMed PMID: 27077140. Pubmed Central PMCID: PMC4827765. Epub 2016/04/15. eng

53. Latulipe C, Quandt SA, Melius KA, Bertoni A, Miller DP Jr, Smith D, et al. Insights Into Older Adult Patient Concerns Around the Caregiver Proxy Portal Use: Qualitative Interview Study. Journal of medical Internet research. 2018;20(11):e10524 PubMed PMID: 30389654. Pubmed Central PMCID: PMC6240158. Epub 2018/11/06. eng.

54. Logue MD, Effken JA. An exploratory study of the personal health records adoption model in the older adult with chronic illness. Inform Prim Care. 2012;20(3):151-69 PubMed PMID: 23710840. Epub 2012/01/01. eng.

55. Lyles CR, Sarkar U, Ralston JD, Adler N, Schillinger D, Moffet HH, et al. Patient-provider communication and trust in relation to use of an online patient portal among diabetes patients: The Diabetes and Aging Study. J Am Med Inform Assoc. 2013;20(6):1128-31 PubMed PMID: 23676243. Pubmed Central PMCID: 3822118.

56. Nahm ES, Zhu S, Bellantoni M, Keldsen L, Charters K, Russomanno V, et al. Patient Portal Use Among Older Adults: What Is Really Happening Nationwide? J Appl Gerontol. 2018;1:733464818776125 PubMed PMID: 29779422. Epub 2018/05/22. eng.

57. Nielsen AS, Halamka JD, Kinkel RP. Internet portal use in an academic multiple sclerosis center. J Am Med Inform Assoc. 2012;19(1):128-33 PubMed PMID: 21571744. Pubmed Central PMCID: 3240754.

58. Nippak PMD, Isaac WW, Geertsen A, lkeda-Douglas CJ. Family attitudes towards an electronic personal health record in a long term care facility. J Hosp Admin. 2015;4(3):9-19.

59. Nordfeldt S, Hanberger L, Bertero C. Patient and parent views on a Web 2.0 Diabetes Portal--the management tool, the generator, and the gatekeeper: qualitative study. J Med Internet Res. 2010;12(2):e17 PubMed PMID: 20511179. Pubmed Central PMCID: 2956228.

60. Odlum M, Gordon P, Camhi E, Valdez E, Bakken S. Exploring factors related to the adoption and acceptance of an internet-based electronic personal health management tool (EPHMT) in a low income, special needs population of people living with HIV and AIDS in New York City. Stud Health Technol Inform. 2014;201:145-52 PubMed PMID: 24943537. Epub 2014/06/20. eng.

61. Osborn CY, Mayberry LS, Wallston KA, Johnson KB, Elasy TA. Understanding patient portal use: implications for medication management. J Med Internet Res. 2013;15(7):e133 PubMed PMID: 23823974. Pubmed Central PMCID: 3713921.

62. Pai HH, Lau F, Barnett J, Jones S. Meeting the health information needs of prostate cancer patients using personal health records. Curr Oncol. 2013; 20(6):e561-9 PubMed PMID: 24311957. Pubmed Central PMCID: PMC3851353. Epub 2013/12/07. eng.

63. Peremislov D. Patient Use of the Electronic Communication Portal in Management of Type 2 Diabetes. Comput Inform Nurs. 2017;35(9):473-82 PubMed PMID: 28323648. Epub 2017/03/23. eng.

64. Electronic Patient Portals: Patient and Provider Perceptions. 2018. Available from: http://www.himss.org/ojni. Cited 15th, April 2008.

65. Price-Haywood EG, Harden-Barrios J, Ulep R, Luo Q. eHealth Literacy: Patient Engagement in Identifying Strategies to Encourage Use of Patient Portals Among Older Adults. Popul Health Manag. 2017;20(6):486-94 PubMed PMID: 28384076.

66. Price-Haywood EG, Luo Q, Monlezun D. Dose effect of patient-care team communication via secure portal messaging on glucose and blood pressure control. J Am Med Inform Assoc. 2018;25(6):702-8 PubMed PMID: 29444256.

67. Ronda MC, Dijkhorst-Oei LT, Gorter KJ, Beulens JW, Rutten GE. Differences between diabetes patients who are interested or not in the use of a patient Web portal. Diab Technol Ther. 2013;15(7):556-63 PubMed PMID: 23777369. Pubmed Central PMCID: PMC3709590. Epub 2013/06/20. eng.

68. Ryan BL, Brown JB, Terry A, Cejic S, Stewart M, Thind A. Implementing and Using a Patient Portal: A qualitative exploration of patient and provider perspectives on engaging patients. J Innov Health Inform. 2016;23(2):848 PubMed PMID: 27869582. Epub 2016/11/22. eng.

69. Sarkar U, Karter AJ, Liu JY, Adler NE, Nguyen R, Lopez A, et al. The literacy divide: health literacy and the use of an internet-based patient portal in an integrated health system-results from the diabetes study of northern California (DISTANCE). J Health Commun. 2010;15(Suppl 2):183-96 PubMed PMID: 20845203. Pubmed Central PMCID: 3014858.

70. Sarkar U, Karter AJ, Liu JY, Adler NE, Nguyen R, Lopez A, et al. Social disparities in internet patient portal use in diabetes: evidence that the digital divide extends beyond access. J Am Med Inform Assoc. 2011;18(3): 318-21 PubMed PMID: 21262921. Pubmed Central PMCID: 3078675.

71. Schneider H, Hill S, Blandford A. Patients Know Best: Qualitative Study on How Families Use Patient-Controlled Personal Health Records. J Med Internet Res. 2016;18(2):e43 PubMed PMID: 26912201. Pubmed Central PMCID: 4785240

72. Sharp LK, Carvalho P, Southward M, Schmidt ML, Jabine LN, Stolley MR, et al. Electronic Personal Health Records for Childhood Cancer Survivors: An Exploratory Study. J Adolesc Young Adult Oncol. 2014;3(3):117-22 PubMed PMID: 25276495. Pubmed Central PMCID: PMC4171113. Epub 2014/10/03. eng.

73. Sieck CJ, Hefner JL, Schnierle J, Florian H, Agarwal A, Rundell K, et al. The Rules of Engagement: Perspectives on Secure Messaging From Experienced Ambulatory Patient Portal Users. JMIR medical informatics. 2017;5(3):e13 PubMed PMID: 28676467. Pubmed Central PMCID: PMC5516097. Epub 2017/07/06. eng. 
74. Smith SG, O'Conor R, Aitken W, Curtis LM, Wolf MS, Goel MS. Disparities in registration and use of an online patient portal among older adults: findings from the LitCog cohort. J Am Med Inform Assoc. 2015;22(4):888-95 PubMed PMID: 25914099. Pubmed Central PMCID: PMC4810779. Epub 2015/04/29. eng.

75. Tenforde M, Nowacki A, Jain A, Hickner J. The association between personal health record use and diabetes quality measures. J Gen Intern Med. 2012; 27(4):420-4 PubMed PMID: 22005937. Pubmed Central PMCID: 3304034.

76. Tieu L, Sarkar U, Schillinger D, Ralston JD, Ratanawongsa N, Pasick R, et al. Barriers and Facilitators to Online Portal Use Among Patients and Caregivers in a Safety Net Health Care System: A Qualitative Study. J Med Internet Res. 2015;17(12):e275 PubMed PMID: 26681155. Pubmed Central PMCID: PMC4704882. Epub 2015/12/19. eng.

77. Tieu L, Schillinger D, Sarkar U, Hoskote M, Hahn KJ, Ratanawongsa N, et al. Online patient websites for electronic health record access among vulnerable populations: portals to nowhere? J Am Med Inform Assoc. 2017; 24(e1):e47-54 PubMed PMID: 27402138. Pubmed Central PMCID: PMC6080722. Epub 2016/07/13. eng.

78. Tom JO, Mangione-Smith R, Solomon C, Grossman DC. Integrated personal health record use: association with parent-reported care experiences. Pediatrics. 2012;130(1):e183-90 PubMed PMID: 22689872.

79. Urowitz S, Wiljer D, Dupak K, Kuehner Z, Leonard K, Lovrics E, et al. Improving diabetes management with a patient portal: a qualitative study of diabetes selfmanagement portal. J Med Internet Res. 2012;14(6):e158 PubMed PMID: 23195925. Pubmed Central PMCID: PMC3510725. Epub 2012/12/01. eng.

80. van den Heuvel SCGH, Meije D, Regeer EJ, Sinnema H, Riemersma RF, Kupka RW. The user experiences and clinical outcomes of an online personal health record to support self-management of bipolar disorder: A pretestposttest pilot study. J Affect Disord. 2018;238:261-8.

81. Wade-Vuturo AE, Mayberry LS, Osborn CY. Secure messaging and diabetes management: experiences and perspectives of patient portal users. J Am Med Inform Assoc. 2013;20(3):519-25 PubMed PMID: 23242764. Pubmed Central PMCID: PMC3628058. Epub 2012/12/18. eng.

82. Wagner PJ, Dias J, Howard S, Kintziger KW, Hudson MF, Seol YH, et al. Personal health records and hypertension control: a randomized trial. J Am Med Inform Assoc. 2012;19(4):626-34 PubMed PMID: 22234404. Pubmed Central PMCID: 3384099

83. Wagner PJ, Howard SM, Bentley DR, Seol YH, Sodomka P. Incorporating patient perspectives into the personal health record: implications for care and caring. Perspect Health Inform Manag. 2010;7:1e PubMed PMID: 21063546. Pubmed Central PMCID: 2966356

84. Weppner WG, Ralston JD, Koepsell TD, Grothaus LC, Reid RJ, Jordan L, et al. Use of a shared medical record with secure messaging by older patients with diabetes. Diabetes Care. 2010;33(11):2314-9 PubMed PMID: 20739686. Pubmed Central PMCID: 2963486.

85. Williamson RS, Cherven BO, Gilleland Marchak J, Edwards P, Palgon M, Escoffery

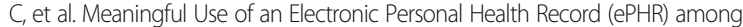
Pediatric Cancer Survivors. Appl Clin Inform. 2017;8(1):250-64 PubMed PMID: 28293684. Pubmed Central PMCID: PMC5373768. Epub 2017/03/16. eng.

86. Zickmund SL, Hess R, Bryce CL, McTigue K, Olshansky E, Fitzgerald K, et al. Interest in the use of computerized patient portals: role of the providerpatient relationship. J Gen Intern Med. 2008;23(Suppl 1):20-6 PubMed PMID: 18095039. Pubmed Central PMCID: 2338160

87. Gordon P, Camhi E, Hesse R, Odlum M, Schnall R, Rodriguez M, et al. Processes and outcomes of developing a continuity of care document for use as a personal health record by people living with HIV/AIDS in New York City. Int J Med Inform. 2012;81(10):e63-73 PubMed PMID: 22841825. Pubmed Central PMCID: 4447096

88. Luque AE, van Keken A, Winters P, Keefer MC, Sanders M, Fiscella K. Barriers and Facilitators of Online Patient Portals to Personal Health Records Among Persons Living With HIV: Formative Research. JMIR Res Protoc. 2013;2(1):e8 PubMed PMID: 23612564. Pubmed Central PMCID: 3628162

89. Martinez M, Baum A, Gomez Saldano AM, Gomez A, Luna D, Gonzalez Bernaldo de Quiros F. Predictive variables of the use of personal health record: the Hospital Italiano de Buenos Aires study. Stud Health Technol Inform. 2013;192:1171 PubMed PMID: 23920945. Epub 2013/08/08. eng.

90. Rocha RA, Romeo AN, Norlin C. Core features of a parent-controlled pediatric medical home record. Stud Health Technol Inform. 2007;129(Pt 2): 997-1001 PubMed PMID: 17911865. Epub 2007/10/04. eng.
91. Kushniruk AW, Turner P. Who's users? Participation and empowerment in socio-technical approaches to health IT developments. Stud Health Technol Inform. 2011;164:280-5 PubMed PMID: 21335724.

92. Niazkhani Z, Pirnejad H, de Bont A, Aarts J. CPOE in Non-Surgical Versus Surgical Specialties: A Qualitative Comparison of Clinical Contexts in the Medication Process. Open Med Inform J. 2010;4:206-13 PubMed PMID: 21594008. Pubmed Central PMCID: 3096890.

93. Pirnejad H, Niazkhani Z, Aarts J, Bal R. What makes an information system more preferable for clinicians? a qualitative comparison of two systems. Stud Health Technol Inform. 2011;169:392-6 PubMed PMID: 21893779.

94. Niazkhani Z, van der Sijs H, Pirnejad H, Redekop WK, Aarts J. Same system, different outcomes: comparing the transitions from two paper-based systems to the same computerized physician order entry system. Int J Med Inform. 2009;78(3):170-81 PubMed PMID: 18760660.

95. O'Connor S, Hanlon P, O'Donnell CA, Garcia S, Glanville J, Mair FS. Understanding factors affecting patient and public engagement and recruitment to digital health interventions: a systematic review of qualitative studies. BMC Med Inform Decis Making. 2016;16(1):120 PubMed PMID: 27630020. Pubmed Central PMCID: 5024516.

96. Caldwell HD, Minkoff NB, Murthy K. Patient web portals and patientprovider relationships: a summary perspective. Int J Technol Assess Health Care. 2017;33(1):63-8 PubMed PMID: 28434422. Epub 2017/04/25. eng.

97. Kabene SM, Orchard C, Howard JM, Soriano MA, Leduc R. The importance of human resources management in health care: a global context. Hum Resour Health. 2006;4:20 PubMed PMID: 16872531. Pubmed Central PMCID: 1552082.

98. Epping-Jordan JE, Pruitt SD, Bengoa R, Wagner EH. Improving the quality of health care for chronic conditions. Qual Safety Health Care. 2004;13(4):299305 PubMed PMID: 15289634. Pubmed Central PMCID: 1743863.

99. Yau GL, Williams AS, Brown JB. Family physicians' perspectives on personal health records: qualitative study. Can Fam Physician. 2011;57(5):e178-84 PubMed PMID: 21642732. Pubmed Central PMCID: 3093606.

100. Wynia MK, Torres GW, Lemieux J. Many physicians are willing to use patients' electronic personal health records, but doctors differ by location, gender, and practice. Health Affairs. 2011;30(2):266-73 PubMed PMID: 21289348.

101. Witry MJ, Doucette WR, Daly JM, Levy BT, Chrischilles EA. Family physician perceptions of personal health records. Perspect Health Inform Manag. 2010;7:1d PubMed PMID: 20697465. Pubmed Central PMCID: 2805556.

102. Mishuris RG, Stewart M, Fix GM, Marcello T, Mclnnes DK, Hogan TP, et al. Barriers to patient portal access among veterans receiving home-based primary care: a qualitative study. Health Expect. 2015;18(6):2296-305 PubMed PMID: 24816246. Pubmed Central PMCID: 5810689.

103. Horan TA, Botts NE, Burkhard RJ. A multidimensional view of personal health systems for underserved populations. J Med Internet Res. 2010;12(3): e32 PubMed PMID: 20685644. Pubmed Central PMCID: 2956321.

104. Kaelber DC, Jha AK, Johnston D, Middleton B, Bates DW. A research agenda for personal health records (PHRs). J Am Med Inform Assoc. 2008;15(6):72936 PubMed PMID: 18756002. Pubmed Central PMCID: 2585530.

105. Jung SY, Lee K, Hwang H, Yoo S, Baek HY, Kim J. Support for Sustainable Use of Personal Health Records: Understanding the Needs of Users as a First Step Towards Patient-Driven Mobile Health. JMIR mHealth uHealth. 2017; 5(2):e19 PubMed PMID: 28232300. Pubmed Central PMCID: 5344982.

106. Kooij L, Groen WG, van Harten WH. Barriers and Facilitators Affecting Patient Portal Implementation from an Organizational Perspective: Qualitative Study. J Med Internet Res. 2018;20(5):e183 PubMed PMID: 29752253. Pubmed Central PMCID: 5970285

\section{Publisher's Note}

Springer Nature remains neutral with regard to jurisdictional claims in published maps and institutional affiliations. 